$$
\text { 19.2380 }
$$

AMLIFPP/TM-120 ANL/FPP/TM-120

191

$r^{3}$

\title{
DESIGN CONSTRAINTS FOR RF-DRIVEN STEADY-STATE TOKAMAK REACTORS
}

by

David A. Ehst

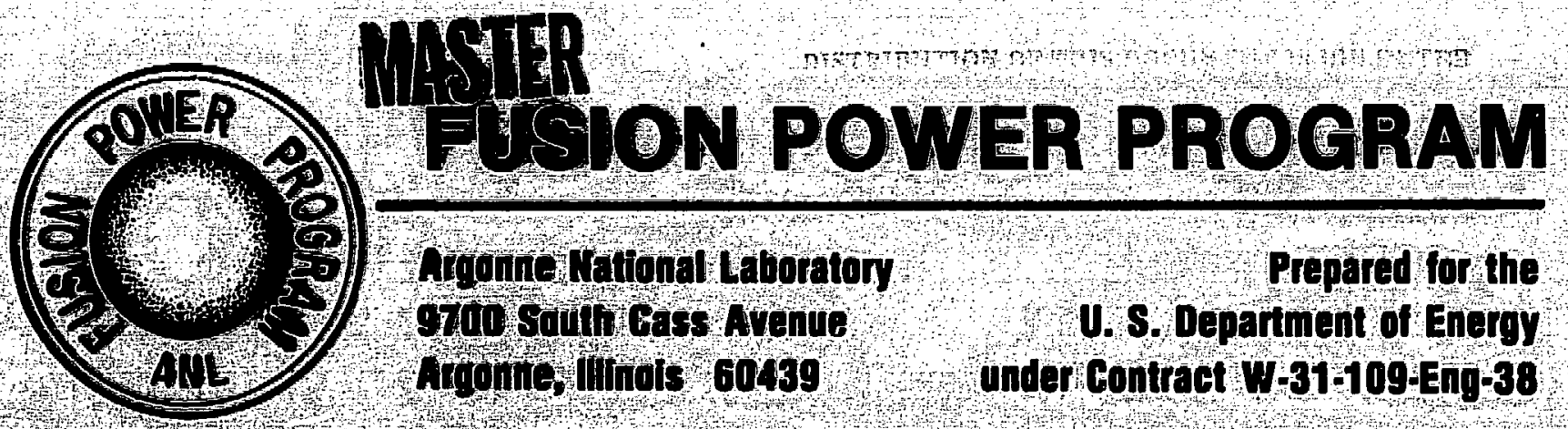




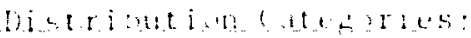

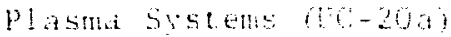

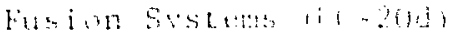

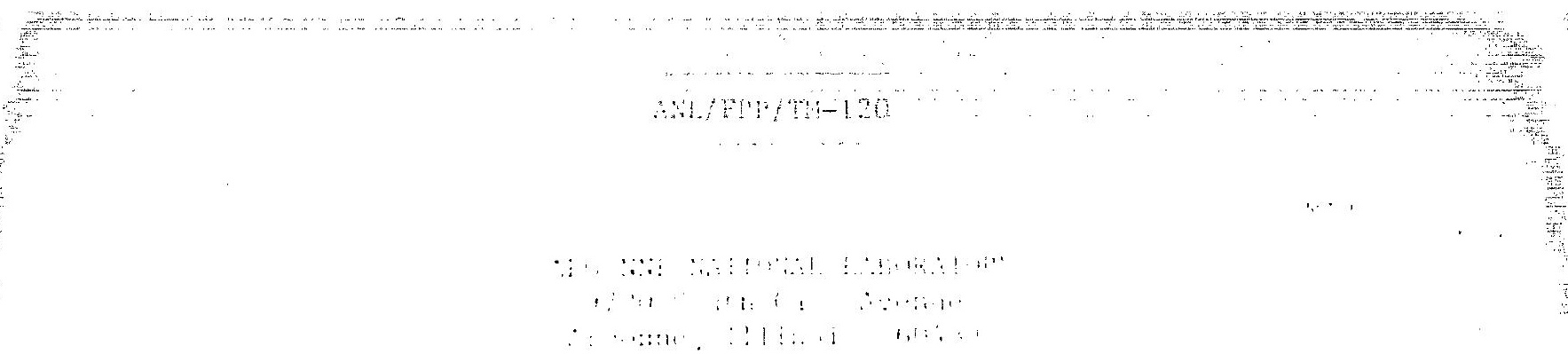

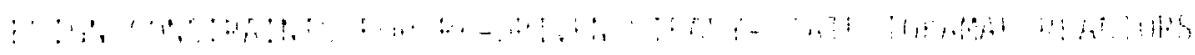

Fobriar: 1979 
ABSTRACT

1. INTRODUCTION

2.1 The Lallia-Brambilla grill ........................... 2

2.2 Quasi-linear theory of current generation $\ldots \ldots \ldots \ldots \ldots \ldots \ldots .3$

2.3 Spatial gradients $\ldots \ldots \ldots \ldots \ldots \ldots \ldots \ldots \ldots \ldots \ldots \ldots \ldots \ldots \ldots$

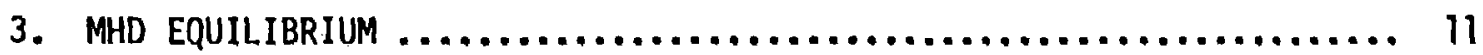

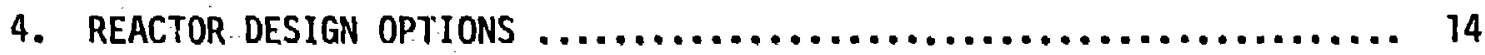

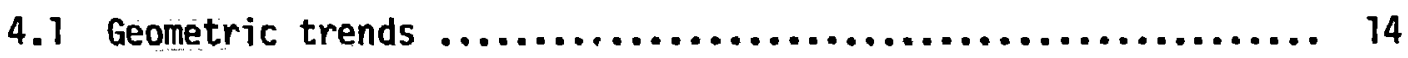

4.2 Centrally peaked current profiles ...................... 15

4.3 Surface current profiles - reference reactor ............. 17

5. REACTOR ENGINEERING $\ldots \ldots \ldots \ldots \ldots \ldots \ldots \ldots \ldots \ldots \ldots \ldots \ldots \ldots \ldots \ldots \ldots \ldots \ldots$

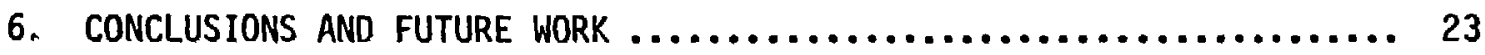

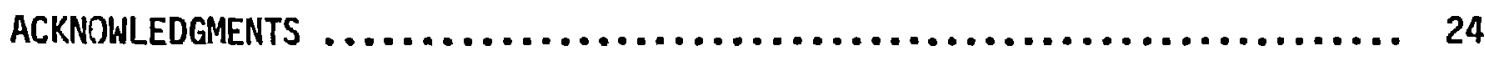

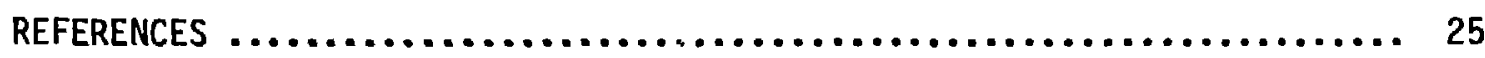

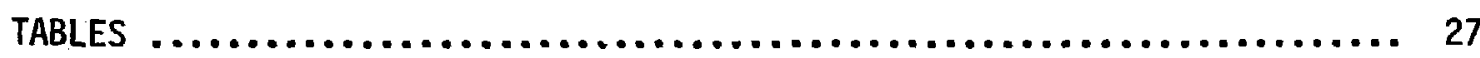

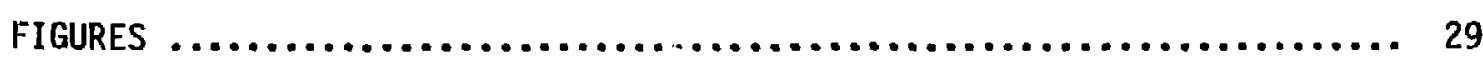




\section{LIST OF TABLES}

No.

Title

I Reactor Survey

II Reactor with Surface Currents at Moderate $B_{t}$

\section{LIST OF FIGURES}

No. Title

Page

$1 \quad$ Typical spectrum from Brambilla grill

$2 \quad$ Centrally peaked current equilibrium 30

$3 \quad$ Surface current equilibrium $\quad 30$

4 Force-free current equilibrium 30

5 Major radius and plasma current for various beta scalings 31

6 Major radius and plasma current for various beta scalings 32

7 Total current and $r f$ power for $\bar{T}_{e}=18 \mathrm{keV}, \alpha_{n}=1.7$, and $n_{\mathrm{z} 1}=1.60$

8 Required $r f$ power for reactor with $\overline{\mathrm{T}}_{\mathrm{e}}=18 \mathrm{keV}$ and $\alpha_{\mathbf{n}}=1.7$ for several spectra

9 Reactor reference profiles

10 Lower hybrid wave accessibility

11 RF system with waveguides routed to external location

12 Typical reactor parameters during startup 


\title{
DESIGN CONSTRAINTS FOR RF-DRIVEN STEADY-STATE TOKAMAK REACTORS
}

\author{
David A. Ehst \\ Applied Physics Division \\ Argonne National Laboratory \\ Argonne, Illinois 60.739
}

\begin{abstract}
Plasma current density profiles are computed due to electron Landau damping of lower hybrid waves launched into model tokamak density and temperature profiles. The total current and current profile shape are chosen consistent with magnetohydrodynamic equilibrium for a variety of temperature and density distributions and plasma beta values. Surface current equilibria appear attractive and are accessible to waves with $n_{z}$ as low as 1.2 . By suitably choosing the spectrum location and width it is possible to drive the $9.8 \mathrm{MA}$ current of a 7.0-m reactor with as 1 ittle as $2.8 \%$ of the fusion power recirculated as $\mathrm{rf}$ input from the waveguides.
\end{abstract}




\section{INTRODUCTION}

Steady-state fusion reactors are a desirable goal in view of the large demands on materials and components in a pulsed reactor and in view of the significant amounts of energy $(\approx 10 \mathrm{GJ})$ that must be stored and transferred in pulsed devices. This report is a study of steady-state tokamak reactors in which radio-frequency $(r f)$ wave sources essentiality replace the conventional ohmic-heating transformer windings. The $r f$ waves thus serve two primary functions: the plasma is heated to ignition, and the plasma is contained by the steady-state toroidal current generated by the rf waves. Radio-frequencydriven tokamaks may offer distinct economic advantages over alternatives such as neutral beam-driven reactors since $r f$ sources operate at high efficiencies and may be remotely located relative to the reactor containment structure. The emphasis of this study is to outline the constraints and benefits associated with rf-driven reactors. While the result is by no means an optimized design for such a reactor, the study does suggest such reactors can be conipetitive with more conventional tokamak reactors.

\section{THEORY OF LOWER HYBRID WAVES IN A TOKAMAK PLASMA}

\subsection{The Lallia-Brambilla grill}

An array of waveguides has been shown to be an effective structure for radiating lower hybrid waves into tokamaks [1-3]. The guides are oriented with the electric field vector parallel to the toroidal magnetic field, and, if each guide is phased $\pi / 2$ relative to its neighbor, a travelling wave is launched which carries momentum in the toroidal direction. The waveguide dimensions determine the parallel wavelength while the number of guides in the array influences the spectral width. 
Figure 1 displays a typical spectrum in the near-vacuum region at the waveguide opening; the spectral intensity is given as a function of the parallel index of refraction, $n_{z}=c k_{z} / \omega$, where $c$ is the speed of 1 ight, $2 \pi / k_{z}$ is the wavelength in the toroidal direction, and $w / 2 \pi$ is the wave frequency. (We assume the tokamak's poloidal magnetic field, B, is small compared to the toroidal component, $B_{t}$, such that the electron guiding centers essentially travel in the toroidal direction.) Also shown in the figure is a rectangular approximation to the actual spectrum which indicates a many-wave spectrum with parallel phase velocities in the range

$$
c / n_{z 1}<\omega / k_{z}<c / n_{z 2}
$$

\subsection{Quasi-linear theory of current generation}

A narrow rectangular spectrum of waves has a parallel electric field $E_{z}$, where

$$
\begin{aligned}
E_{z}^{2} & =\int_{-\infty}^{\infty} d k_{z} k_{z}^{2}\left|\phi_{k z}\right|^{2} \\
& =\Delta k_{z} k_{z 1}^{2}\left|\phi_{k z}\right|^{2}
\end{aligned}
$$

Here we set $\Delta k_{z}=k_{z 1}-k_{z 2}, k_{z 1,2}=\omega n_{z 1,2} / c$, and assumed $\Delta k_{z} \ll k_{z 1}$. The spectral intensity is thus

$$
\left|\phi_{k z}\right|^{2}=\left\{\begin{array}{l}
E_{z}^{2} /\left(k_{z 1}^{2} \Delta k_{z}\right), k_{z 2}<k_{z}<k_{z 1} \\
0, \text { el sewhere. }
\end{array}\right.
$$

According to quasi-linear theory the resonant electrons (those with parallel velocities in the range of parallel wave-phase velocities) will be randomly 
accelerated and decelerated by the $E_{z}$ field, and the distribution of resonant electrons will diffuse in parallel velocity, $v$. The diffusion coefficient is [4]

$$
D^{Q L}=\frac{e^{2}}{m_{e}^{2}} \int_{-\infty}^{\infty} d\left(\frac{k_{z} v}{\omega}\right) \frac{k_{z}^{2}}{v}\left|\phi_{k z}\right|^{2} \pi \delta\left(\frac{k_{z} v}{\omega}-1\right),
$$

where $e$ and $m_{e}$ are the electron charge and mass, respectively. Substituting the expression for the spectral intensity,

$$
D^{Q L}=\left\{\begin{array}{l}
\frac{\mathrm{e}^{2}}{\mathrm{~m}^{2}} \frac{E_{z}^{2}}{\Delta k_{z}} \frac{\pi}{\omega / k_{z}}, \quad \omega / k_{z 1}<v<\omega / k_{z 2} \\
0, \text { elsewhere, }
\end{array}\right.
$$

where $k_{z}$ is averaged over the (narrow) spectrum.

Although the wave electric field tends to diffuse the resonant electrons in $v$, collisions try to impose a Maxwell-Boltzmann distribution upon the electrons. This competition is approximately described $[5,6]$ by the following kinetic equation for the electron distribution function $f(v)$ :

$$
\frac{\partial f}{\partial \tau}=\frac{\partial}{\partial w} D \frac{\partial f}{\partial w}+\frac{\partial}{\partial w}\left(\frac{1}{w^{3}} \frac{\partial f}{\partial w}+\frac{f}{w^{2}}\right),
$$

where

$$
\begin{aligned}
D & =D Q L_{1} / v_{T}^{2} v_{0}, \\
v_{T} & =\sqrt{T_{e} / m_{e}}, \\
w & =v / v_{T}, \\
\tau & =v_{0} t, \text { and }
\end{aligned}
$$




$$
v_{0}=\left(z_{i}+2\right) n_{e} e^{4} \ln N / 4 \pi \varepsilon^{2} m_{e}^{2} V_{T}^{3} .
$$

Here $T_{e}, m_{e}$, and $n_{e}$ are the electron temperature, mass, and density, $\ln \Lambda$ is the Coulomb logarithm, $\varepsilon_{0}$ is the permittivity of free space, and $z_{i}$ is the charge of the ion species in the plasma. This differential equation has been averaged over velocity perpendicular to the magnetic field and is zero dimensional in real space. In the steady state its solution is

$$
f=N\left(\exp -\int \frac{w d w}{1+w^{3} D}\right) .
$$

The coefficient $N$ must vary with $w$ to keep $f$ continuous at the boundaries of the resonant region (where $D$ is discontinuous).

Figure 2 illustrates the electron distribution function when $w^{3} \mathrm{D} \gg 1$, for which case the resonant region, $w_{1} \equiv \omega /\left(k_{z 1} v_{T}\right)<w<w_{2} \equiv \omega /\left(k_{z 2} v_{T}\right)$, is a nearly flat plateau. As the wave electric field is reduced the value of $D$ becomes small, and collisions effectively erode the plateau in phase space. In the 1 imit $w^{3} D \ll 1$, Eq. (1) becomes the Maxwell-Boltzmann distribution. The momentum carried by the electrons is obtained by taking the first moment of $f$, and the plasma's parallel current density is

$$
j=e n e \int_{-\infty}^{\infty} d v v f(\dot{v}) .
$$

Neglecting the small contribution to Eq. (2) from the regions $w<-w_{1}$ and $W_{2}<W$ and assuming the wave electric fields are so large that the plateau in $f$ has zero slope, the current density is approximately 


$$
\begin{aligned}
j & =2.1 \times 10^{-12} n_{e} \sqrt{T_{e}} f\left(w_{1}\right)\left(\frac{w_{2}^{2}-w_{1}^{2}}{2}\right) \\
& =2.1 \times 10^{-10} \frac{n_{e}}{\sqrt{T_{e}}} \exp \left(-\frac{255.9}{n_{z 1}^{2} T}\right)\left(\frac{1}{n_{z 2}^{2}}-\frac{i}{n_{z}^{2}}\right) .
\end{aligned}
$$

In these formulas $j$ is in $A / \mathrm{m}^{2}$ when $n_{e}$ is in $\mathrm{m}^{-3}$ and $\mathrm{T}_{e}$ is in $\mathrm{keV}$; $f\left(w_{1}\right)=\exp \left(-w_{1}^{2} / 2\right) / \sqrt{2 \pi}$.

In the steady state the power transferred by the wave to the resonant electrons is passed on to other particles via collisions. Hence, denoting the collision operator on $f$ by $c(f)$, energy density is dissipated at a rate

$$
\begin{aligned}
p_{r f} & =-\int_{-\infty}^{\infty} d v k \frac{n_{e} m_{e} v^{2}}{2} c(f) \\
& =\int_{-\infty}^{\infty} d w k \frac{n_{e} m_{e} v_{T}^{2} v_{0}}{2} w^{2} \frac{d}{d w} D \frac{d f}{d w} \\
& =1.7 \times 10^{-31} k \frac{n_{e}^{2}}{\sqrt{T_{e}}} \ln \Lambda f\left(w_{1}\right) \ln \left(\frac{1+w_{2}^{3} D}{1+w_{1}^{3} D}\right)^{1 / 3} .
\end{aligned}
$$

When $w_{1}^{3} D>1$ (large electric fields) and for en $\Lambda \approx 18$, this expression is approximately

$$
P_{r f}=1.2 \times 10^{-30} k \frac{n_{e}}{\sqrt{T_{e}}} \exp \left(-\frac{255.9}{n_{z 1}^{2} T_{e}}\right) \ln \left(\frac{n_{z 1}}{n_{z 2}}\right)
$$

A11 units are MKS and keV. $K$ is a correction factor which is obtained from a more realistic two-velocity dimension analysis [7]. In Ref. 7 the authors numerically solved the kinetic equation with quasilinear and Fokker-Planck 
operators and found $x=0.392$. This value will be used in the remainder of our work.

In designing tokamak reactors the local current density must be consistent with MHD equilibrium requirements, and the goal of achieving economical wave-driven currents is essentially the minimization of the power dissipated in doing this. Thus, a useful parameter for study is the local ratio $\mathrm{p}_{\mathrm{rf}} / \mathrm{j}$, which is approximately given by Eqs. (3) and (5):

$$
\frac{P_{r f}}{j}=2.2 \times 10^{-21} n_{e} \frac{\ln \left(n_{z 1} / n_{z 2}\right)}{\left(n_{z 2}^{-2}-n_{z 1}^{-2}\right)} .
$$

This formula points to the important principle that wave-driven reactors be designed to have the highest current density in regions of low-particle density; the ratio $\mathrm{P}_{\mathrm{rf}^{\prime}} / \mathrm{j}$ is independent of temperature. Ir reactor analysis three strategies will generally be considered in order to drive currents in lowdensity plasma regions. First, the average density may be lowered while increasing the average temperatu = keeping the product $n_{e} T_{e}$ constant (the bar denotes a spatial average). Since the plasma beta is proportional to $\overline{n_{e} T_{e}}$ this strategy will reduce the $\mathrm{rf}$ power while keeping the fusion power density relatively constant. Second, the density profile might be varied. As an example, for a given average density a broad, flat profile tends to reduce the central density, which is advantageous if the equilibrium requires a centrally peaked current density. Third, equilibria can be studied which require currents in low-density regions, e.g., surface currents. Finally, Eq. (6) shows $\mathrm{p}_{\mathrm{rf}} / \mathrm{j}$ is influenced by the spectrum location and width. To proceed it becomes necessary to explicitly treat plasma profile effects on the total rf power and current. 


\subsection{Spatial gradients}

We use a cylindrical model of tokamak density and temperature profiles given by

$$
n_{e}(r)=n_{e}\left[1-r^{2} / a^{2}\right]^{\alpha} n
$$

and

$$
T_{e}(r)=T_{e 0}\left[1-r^{2} / a^{2}\right]^{\alpha} T \text {, }
$$

.ith $r$ being the distance from the minor axis and a the minor radius. The total current and power dissipated in the torus are

$$
I=\int_{r_{c}}^{a} j(r) 2 \pi r d r
$$

and

$$
P_{r f}=\int_{r_{c}}^{a} p_{r f}(r) 4 \pi^{2} R r d r,
$$

where $r_{c}$ is the radius of furthest wave penetration and $R$ is the major radius. Using the approximations (3) and (5) and the profiles given by (7a) and (7b) these integrals may be evaluated analytically:

$$
I=6.8 \times 10^{-10} a^{2} n_{e 0} T^{-\frac{1}{2}}\left(n_{z 2}^{-2}-n_{z 1}^{-2}\right) \alpha_{T}^{-1} b^{--k_{\Gamma}}(k, d)
$$

and

$$
P_{\text {rf }}=9.2 \times 10^{-30} \mathrm{Ra}^{2} n_{\mathrm{e} 0} T_{\mathrm{e} 0}^{-\frac{1}{2}} \ln \left(n_{\mathrm{z} 1} / \mathrm{n}_{\mathrm{z} 2}\right) \alpha_{\mathrm{T}}^{-1} \mathrm{~b}^{-\mathrm{h}_{\Gamma}(\mathrm{h}, \mathrm{d})},
$$

where 


$$
\begin{array}{ll}
b=255.9 n_{\mathrm{z} 1}^{-2} T_{\mathrm{e} 0}, & d=b\left(1-r_{\mathrm{c}}^{2} / \mathrm{a}^{2}\right)^{-\alpha_{T},}, \\
k=1 / 2-\alpha_{\mathrm{T}}^{-1}-\alpha_{\mathrm{n}} / \alpha_{\mathrm{T}}, & h=k-\alpha_{\mathrm{n}} / \alpha_{T} .
\end{array}
$$

The ratio of total $\mathrm{rf}$ power to current is thus

$$
\frac{P_{r f}}{I}=1.3 \times 10^{-20} R n_{e 0}\left(1-r_{c}^{2} / a^{2}\right)^{\alpha} n^{/ \alpha_{T}} \frac{\ell n\left(n_{z 1} / n_{z 2}\right)}{\left(n_{z 2}^{-2}-n_{z 1}^{-2}\right)} G(k, h, d),
$$

where $G$ is approximated by a ratio of continued fractions,

$$
G=\frac{\left(\frac{1}{d+} \frac{1-h}{1+} \frac{1}{d+} \frac{2-h}{1+} \frac{2}{d+} \ldots\right)}{\left(\frac{1}{d+} \frac{1-k}{1+} \frac{1}{d+} \frac{2-k}{1+} \frac{2}{d+} \ldots\right)}
$$

As an illustration, consider a wave which penetrates half the distance to the center of a nearly flat $\left(a_{n}=0.3\right)$ density profile with $n_{z 2}=1.45$, $n_{z 1}=1.55, n_{e 0}=9.15 \times 10^{20} \mathrm{~m}^{-3}, R=9.11 \mathrm{~m}$, and $I=12.2 \mathrm{MA}$. This formula predicts $P_{r f} \approx 147 \mathrm{MW}$. Compared to a fusion power output of $2500 \mathrm{MW}$ this represents about $6 \%$ of the output which must be recycled as rf input power to maintain a steady state. The form of Eq. (10) emphasizes the importance of having low values of $n_{e 0}$. Assuming $\beta_{t}$ is fixed this corresponds to high temperature operation. We define $B_{t}=\sum_{j} 2 \mu_{0} \overline{n_{j} T_{j}} / B_{0}^{2}$, where $B_{0}$ is the toroidal field at the major radius and where the bar denotes a spatial average. In the approximate geometry of concentric circular flux surfaces with equal ion and electron densities and temperature our pressure parameterization yields

$$
B_{0}^{2} B_{t} / 2 \mu_{0}=2 n_{e 0} \top_{e 0}(1+\alpha)^{-1} \text {, }
$$

and 


$$
\frac{P_{\text {rf }}}{I}=17 R B_{0}^{2} B_{t} \frac{(1+\alpha)}{T_{e 0}}\left(1-r_{c}^{2} / a^{2}\right)^{\alpha} n^{\prime \alpha} \frac{\ln \left(n_{z 1} / n_{z 2}\right)}{\left(n_{z 2}^{-2}-n_{z 1}^{-2}\right)} G .
$$

To improve the accuracy of our results the electric field amplitude of lower hybrid waves was followed numerically in tokamak-like plasmas. In cylindrical coordinates we assume a uniform wave intensity at the surface and solve

$$
p_{r f}=-\frac{I}{r} \frac{d}{d r} r\left(v_{g r} \omega \frac{\partial \varepsilon}{\partial \omega} \frac{E^{2}}{2}\right)
$$

where $v_{g r}$ is the radial group velocity and the remaining factor in parentheses is the wave energy density. For lower hybrid waves $[8,9]$ the real part of the dielectric function is

$$
\varepsilon_{\mathrm{r}}=\varepsilon_{0}\left[\frac{k_{\mathrm{z}}^{2}}{k^{2}}\left(1-\frac{\omega_{\mathrm{pe}}^{2}}{\omega^{2}}\right)+\frac{k_{\mathrm{r}}^{2}}{k^{2}}\left(1-\frac{\omega_{\mathrm{pe}}^{2}}{\omega^{2}-\Omega_{\mathrm{e}}^{2}}-\frac{\omega_{\mathrm{p} i}^{2}}{\omega^{2}-r_{i}^{2}}\right)\right],
$$

The dispersion relation $\left(\varepsilon_{\boldsymbol{r}}=0\right)$ is

$$
\omega=\omega_{L H}\left(1+\frac{m_{1}}{m_{e}} \frac{k_{z}^{2}}{k^{2}}\right)^{\frac{1}{2}},
$$

and

$$
v_{g r}=\frac{\partial \omega}{\partial k_{r}}=\frac{\left(\omega_{L H}^{2}-\omega^{2}\right) k_{r}}{\omega k^{2}} .
$$

This is a nonlinear differential equation since $p_{r f}$, given by (4), is a function of $E$. In solving this the cyclotron frequencies, $\Omega_{e}$ and $\Omega_{i}$, are assumed constant, the plasma frequencies, $\omega_{\mathrm{pe}}$ and $\omega_{\mathrm{pi}}$, and lower hybrid frequency, 
$\omega_{L H}=\left(\omega_{p i}^{-2}+\Omega_{e}^{-1} \Omega_{i}^{-1}\right)^{-\frac{1}{2}}$, vary with $r$ according to $(7)$, and the radial wave number, $k_{r}$, is an additional function of $r$, given by the dispersion relation with $k^{2}=k_{r}^{2}+k_{z}^{2}$. Both $\omega$ and $k_{2}$ are constants; the ion mass, $m_{1}$, is set at 2.5 times the proton mass to simulate a DT plasula. From the solution to this equation, $E(r)$, the diffusion coefficient, $D(r)$, and distribution function, (1), are known as functions of radius. Consequently the current and power density profiles are found from (2) and (4), and the total current and dissipated power are known from (8) and (9).

\section{MHD EQUILIBRIUM}

A constraint on reactor design is that the current density and pressure profiles be consistent with MHD equilibrium. A number of equilibria have been computed by solving the Grad-Shafranov equation for the poloidal flux function, $\psi(p, h)[10,11]:$

$$
\frac{\partial^{2} \psi}{\partial \rho^{2}}-\frac{1}{\rho} \frac{\partial \psi}{\partial \rho}+\frac{\partial^{2} \psi}{\partial h^{2}}=-4 \pi^{2}\left(\mu_{0} \rho^{2} \frac{d \rho}{d \psi}+\frac{1}{2} \frac{d F^{2}}{d \psi}\right)
$$

We have defined $\rho$ as the distance from the symmetry axis and $h$ as the distance from the equatorial plane; a scalar pressure, $p(\psi)=\sum_{j} n_{j}(\psi) T_{j}(\psi)$, is assumed with the density and temperature being constant on flux surfaces, $\psi(\rho, h)=$ constant. We require $\psi=$ constant on the boundary

$$
\left\{\begin{array}{l}
h=k a \sin t \\
\rho=R+a \cos (t+d \sin t),
\end{array}\right.
$$

where $0 \leq t \leq 2 \pi$. The current and pressure profiles, plasma beta, and total current in equilibrium depend on the pressure and diamu jnetic function, $F^{2}(\psi)$, specified in (12). We set $p(\psi)=p_{0} \hat{\psi}^{\alpha}=\sum_{j} n_{j 0} \hat{\psi}^{\alpha} n_{j 0} \hat{\imath}^{\alpha} T$, where 
$\hat{\psi}=\left(\dot{\psi}_{1 \text { imiter }}-\psi\right) /\left(\psi_{\text {1imiter }}-\psi_{\text {magnetic axis }}\right)$; near the magnetic axis these density and temperature profiles have the approximate form given by (7a) and (7b) if $k=1$ and $R / a \gg 1$. Note $\alpha=a_{n}+a_{T}$.

Figure 2 displays the current density $j$ and pressure $p$ in the equatorial plane of a circular plasma $(k=1, d=0)$ with an aspect ratio $A=R / a=3$, $\alpha=1.4, \beta_{t}=0.06$, and safety factor, $q(\psi)$, varying between unity at the magnetic axis and 3.0 at the boundary. This particular equilibrium results from choosing

$$
F^{2}(\psi)=F_{0}^{2}\left(1-0.097 \hat{\psi}^{1.7}\right) \text {, }
$$

where $F_{0}$ is the product of $\rho$ and the toroidal vacuum magnetic field. This equilibrium is typical of those with what we shall call centrally peaked densities; al though $j(\rho)$ is asymmetric due to toroidal effects, the current peaks at only one interior location.

By setting $F^{2}=F z\left(1-0.299 \hat{\psi}^{2} \cdot{ }^{9}\right)$ and $\alpha=2.0$ the equilibrium in Fig. 3 results. This particular case is for $A=3.0, k=3.3$, and $d=0.25$. The noncircular plasma shape may be conducive to higher beta stability [12-16]; if, for example, $q(\psi)$ varies between 1.3 and 3.9 then $\beta_{t}=0.07$ while if $q$ varies between 1.0 and 3.0 then $\beta_{t}=0.12$. This current profile is hollow in the center and is typical of what may be termed a surface current equilibrium.

Even higher beta equilibria exist if "force-free" paramagnetic currents flow on the plasma surface $[17,18]$. Figure 4 is an example, taken from Ref. 17, with $A=2.5, k=1.0, d=0.0, \alpha=2.0$, and $F^{2}=F_{0}^{2}\left[1-C_{1} \hat{\psi}^{2} \cdot 0+C_{2}\left(\hat{\psi}^{1 \cdot 9}-\hat{\psi}^{2 \cdot 0}\right)\right]$, where $C_{2} \approx 20$. This example has $\beta_{t}=0.16$ when $q(\psi): q(0)=1.0$. We note that peak betas of twenty per cent have been experimentally demonstrated in SPICA [19], a torus with $A=3.0$, $\kappa=1.0, d=0.0$, and $q(\psi)=q(a)=1.7$. While the force-free surface currents 
in the experiment are obtained by implosive heating of the plasma, the intriguing possibility exists that these currents could be driven in a steady-state by $r f$ wave damping.

In our examination of rf-driven tokamaks both centrally peaked and surface currents will be considered, and in each case the correct total current, I, for equilibrium will be computed from Eq. (12). Likewise, the appropriate flux surface geometry, $\psi(\rho, h)$, will be used to create two-dimensional density and temperature profiles from which the fusion power production will be found:

$$
P_{\mathrm{f}}=\int_{\psi_{\text {magnetic axis }}^{\psi}}^{\psi} n_{\mathrm{DT}}(\psi)^{2} \frac{\left\langle\mathrm{\sigma v}\left[\mathrm{T}_{\mathrm{DT}}(\psi)\right]\right\rangle}{4} \cup \frac{\mathrm{dV}}{\mathrm{d} \psi} \mathrm{d} \psi \text {, }
$$

where $d V$ is the differential toroidal volume, $d V / d \psi$ is the Jacobian between $\rho$, $h$, and $\psi$ coordinates, and $U=17.58 \mathrm{MeV}$. The DT density and temperature, $n_{D T}$ and $T_{D T}$, are computed from the zero-dimensional steady-state particle and power balance equations [11], for which the average electron temperature, impurity content, and profile parameters, $\alpha_{n}$ and $\alpha_{T}$ have been specified. The alpha particle density is determined from the fusion rate, and $\beta_{t}$ is consistent with the MHD equilibrium. Our subsequent analysis of the required $r f$ power for a given reactor configuration will be approximate to the extent that the profiles given by (7a) and (7b) are in disagreement with the two-dimensional profiles used in (13). However, in the large aspect ratio limit, near the magnetic axis, $\psi \propto r^{2}$ and the profiles are nearly the same. We stress that the equilibrium I and $\psi(\rho, h)$ are functions of the major radius $R$ and vacuum toroidal magnetic field; we assume a toroidal field strength of $9.0 \mathrm{~T}$ at the inner magnet surface and a blanket/shield/vacuum gap spacing of $1.2 \mathrm{~m}$ on the inside of the torus. 


\section{REACTOR DESIGN OPTIONS}

\subsection{Geometric trends}

From Ref. 11 we may approximate

$$
P_{E}=C^{-} R^{3} K A^{-2} \beta_{t}^{2} B_{0}^{4}\left[(1+\alpha)^{2} \alpha^{-3 / 4}\left\langle\sigma v\left(T_{10}\right)\right\rangle T_{10}^{-2}\right]
$$

and

$$
I: C \cdots k A^{-2} R B_{0} q^{-1} \text {, }
$$

so

$$
\frac{P_{f}}{I}=\operatorname{CR}^{2} \beta_{t}^{2} B_{0}^{3} q\left[(1+\alpha)^{2} \alpha^{-3 / 4}\left(\alpha v\left(T_{10}\right)\right) T_{i 0}^{-2}\right] \text {, }
$$

with $C=6 \times 10^{23}$.

Consider first the influence of aspect ratio on reactor design, recalling that an rf-driven reactor may require no central solenoid with primary Ohmic heating $(\mathrm{OH})$ coils and thus could be designed with smaller A than conventional tokamaks. Since the maximum stable $B_{t}$ is thought to scale inversely with some power of $A$ [16] we see from (14) that reactor size, $R$, is reduced for a fixed $P_{f}$ and $B_{0}$ by going to small $A$. However, for a fixed maximum toroidal (TF) field at the magnet the value of $B_{0}^{4}$ decreases rapidly upon going to small $A$ : $B_{0}=9 . n T\left(1-A^{-1}-1.2 R^{-1}\right)$. Minimum machine sizes occur for $A=2.5$ for typical $B_{t}$ scalings [11]. In addition, (16) indicates that I tends to large values for fixed $P_{f}$ as $A$ becomes small. These trends have been numerically confimed [11] and are illustrated in Fig. 5; based on the figure, $A=3$ is chosen for the remainder of our investigation, this representing a compromise between reasonable major radius and plasma current.

For a fixed $A$ and $P_{f}$ and for $B_{t}$ increasing with $K[16],(14)$ suggests that $R$ decreases by going to more elongated plasmas. However, the required 
plasma current increases rapidly for a fixed $P_{f}$ once $k$ exceeds about two [11], as shown in Fig. 6. The optimum $k$ depends on detailed cost breakdowns for a power plant; our studies focus on values in the range $1.0 \leq k \leq 1.65$.

A critical economic parameter of the rf-driven tokamak reactor is the ratio of $r f$ power to fusion power, which is roughly given by the ratio of (11) to (16):

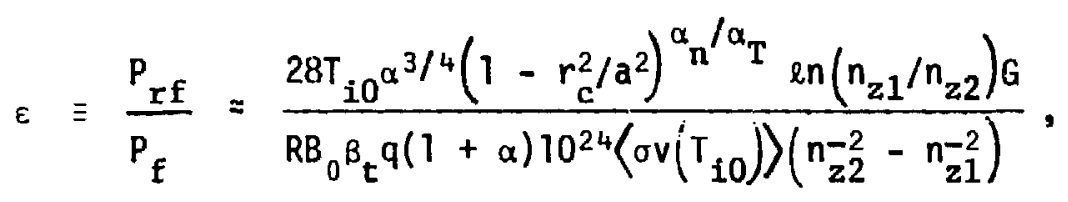

where we assumed $\mathrm{T}_{\mathrm{e} 0}=\mathrm{T}_{10}$. In the range of interest to fusion power $\left\langle\sigma v\left(T_{i 0}\right)\right\rangle \sim T_{i 0}^{2}$, and we can illustrate strong influences on reactor design by rewriting (17) as

$$
\varepsilon \propto\left(\mathrm{RB}_{0} \beta_{\mathrm{t}} \mathrm{T}_{\mathrm{i} 0}\right)^{-1}
$$

This last expression confirms the claim in Sec. 2.2 that higher plasma temperatures are beneficial to reactor economics for fixed $\beta_{t}$. In addition, large $R$, $B_{0}$, and $B_{t}$ are desirable, which suggests large, high power reactors are more favorable. Formula (18) is a generalization of the $\varepsilon$ expression found in Fisch's work $[5,6]$. Fisch did not obtain the complete temperature dependence since he ignored the temperature variation of $\langle\sigma v\rangle$ in his apprcximate formula. In addition Fisch adopted a particular scaling, law for $\beta_{t}: \beta_{t} \propto q^{-2} i^{-1}$.

\subsection{Centrally peaked current profiles}

An extensive survey was made of reactors with equilibria typified by Fig. 2 with $A=3.0, k=1.0, d=0.0, \alpha=1.4, q(a)=3.0$, and $B_{t}=0.06$. The reactor major radius and plasma current were first computed for a fusion power output $\mathbf{P}_{\mathbf{f}}=5000 \mathrm{MW}$ and for a variety of average electron temperatures 
and density profiles: $\bar{T}_{\mathbf{e}}=10,18,26,34 \mathrm{keV}$ and $a_{\mathrm{n}}=0.3,0.7,1.1$. The second step in the survey process was the computation of the current profiles and $r f$ power dissipation in these candidate reactors; by varying the incident wave intensity, spectrum center, and spectrum width it was possible to match the required total plasma current with centraliy peaked current densities in each reactor and to minimize the required $\mathrm{rf}$ power.

The survey results may be briefly summarized. Increasing $\vec{T}_{e}$ above $8 \mathrm{keV}$ is beneficial at first because the lower density plasma dissipates less power, as suggested by (18). However, above $20-40 \mathrm{keV}$ the fusion power density starts to decrease so rapidly that the reactor volume must increase, and the larger major radius requires higher total plasma currents. Numerically it is found that $E$ is a minimum for $\bar{T}_{e} \approx 18 \mathrm{keV}$. For all peaked currents with $P_{f}=5000$ MW the best value found for $\varepsilon$ was about $3.8 \%$. The smallest such reactor (with $\alpha_{n}=1.1, \bar{T}_{e}=18 \mathrm{keV}, B_{\max }=9 \mathrm{~T}$ ) had $\mathrm{R}=9.8 \mathrm{~m}$. In view of the large major radii required for $5000 \mathrm{MW}$ reactors, the remainder of our investigation concentrated on smaller reactors.

The parameter survey was repeated for the same centrally peaked current equilibria in 2500-lin reactors. $\bar{T}_{\mathrm{e}} \approx 18 \mathrm{keV}$ was again found optimum, but in this case the best value of $\varepsilon$ was about $4.2 \%$. This best case (with $\alpha_{n}=1.1, B_{\max }=9 \mathrm{~T}$ ) requires $R=8.2 \mathrm{~m}$, which confirms the trend to larger $\varepsilon$ at smaller $R$, suggested by (18). The increase in circulating power, represented by $\varepsilon$, may well be offset by the decrease in reactor capital cost at the smaller sizes.

The chief disadvantage of all centrally peaked current reactors is the low index of refraction required for the $r f$ to penetrate to the hot central plasma regions. In order to achieve the minimum values of $\varepsilon$, it is necessary to choose the $n_{z}$ spectrum below about 1.3. In fact the central plasma vill be inaccesible to lower hybrid waves with such high parallel phase ve? xcities $[5,8]$; such 
waves penetrate a limited distance and are reflected. This consideration quite naturally leads to the examination of reactor plasmas with surface currents, described in the next section.

\subsection{Surface current profiles - reference reactor}

A survey of reactors with surface currents (Fig. 3 with $A=3.0, k=1.3$, $d=0.25, \alpha=2.0, q=1.3-3.9$, and $\left.\beta_{t}=0.07\right)$ was done for a moderate-sized radius, $\mathrm{R}=7.0 \mathrm{~m}$, and for a maximum toroidal field typical of NbTi superconductor, $B_{\max }=9.0 \mathrm{~T}$. The inner blanket/shield thickness was set at $1.0 \mathrm{~m}$ [20], and the vacuum scrape=off region was assumed to be $0.2 \mathrm{~m}$, which yields a field on axis of $4.46 \mathrm{~T}$. For the calculations, an impurity content of $0.5 \%$ oxygen and $5.0 \%$ beryllium is assumed which results in $z_{\text {eff }} \approx 1.7$.

The survey results for various $\bar{T}_{e}$ and $\alpha_{n}$ values are given in Table I. Fusion power density is a maximum for average ion temperatures approximately equal to $13 \mathrm{keV} /\left(1+\alpha_{\mathrm{T}}\right)[11]$; for $\alpha_{\mathrm{T}}=1.1,0.7$, and 0.3 this corresponds to $\bar{T}_{i}=\bar{T}_{e}=6.2 \mathrm{keV}, 7.6 \mathrm{keV}$, and $10.0 \mathrm{keV}$, respectively. For the higher temperatures in the table the power density and total fusion power accordingly decrease with $\overline{\mathrm{T}}_{e}$. Note likewise that for a fixed $\overline{\mathrm{T}}_{\mathrm{e}}$ the low values of $\alpha_{\mathrm{T}}$ bring the power output closest to the maximum. On the premise that fusion outputs less tinan about $2000 \mathrm{MW}$ are impractical for reactors with $\mathrm{R}=7.0 \mathrm{~m}$ and based on our previous results for centrally peaked currents we will focus on the subset of reactor candidates with $\overline{\mathrm{T}}_{\mathrm{e}}=18 \mathrm{keV}$.

The plasma cross-sectional area for this mildly noncircular reactor with $R=7.0 \mathrm{~m}, A=3.0, k=1.3$, and $d=0.25$ is $X=21.9 \mathrm{~m}^{2}$, and an effective minor radius is used in the cylindrical model for $r f$ current generation: $a \equiv \sqrt{x / \pi}=2.64 \mathrm{~m}$.

Figure 7 displays the total current and $r f$ power for the reactor with $\bar{T}_{e}=18 \mathrm{keV}$ and $\alpha_{\mathfrak{n}}=1.7$ for a variety of spectra. The percentage depth of 
rf penetration is indicated along the curves. Note that as the spectrum narrows deeper penetration occurs with the total I remaining constant. The penalty accompanying the deeper penetration is an increased $\mathrm{P}_{\mathrm{rf}}$. The results also indicate that $\log$ I varies linearly with $\log \mathrm{P}_{\mathbf{r f}}$, the slope depending on $\alpha_{n}$. During the start-up phase of reactor operation with a fixed spectrum the total current and depth of penetration increase with $\mathrm{P}_{\mathbf{r f}}$. The intersection of the curves with the dashed line at 9.81 MA determines the required $P_{r f}$ and depth of penetration. This information for the reactor with $\alpha_{n}=1.7$ is in turn plotted in Fig. 8 for several values of $n_{z 1}$.

The open circles in Fig. 8 correspond to $n_{z 2}=1.2$ and demarcate the approximate accessibility limit for surface penetration. Referring to Fig. 3 we observe the current peaks $34 \%$ of the way in on the outer edge of the plasma and $17 \%$ on the inner side. Taking the average value, we shall require that $\mathrm{rf}-$ driven currents penetrate $25 \%$ of the distance into the plasma. Figure 8 shows that the spectrum with $n_{z 1}=1.45$ requires at least 90 MW to generate currents. The spectrum with $n_{z}=1.56-1.80$ achieves $25 \%$ penetration with only 65 MW. The best case, $n_{z}=1.20-1.60$, achieves the required penetration with about $56 \mathrm{MW}$. From Table I we find the corresponding $\varepsilon=2.8 \%$. For the reactors with $\alpha_{n}=$ 1.3 and 0.9 the best results were $P_{\mathrm{rf}}=70 \mathrm{MW}$ and $\mathrm{P}_{\mathrm{rf}}=85 \mathrm{MW}$, corresponding respectively to $\varepsilon=4.1 \%$ and $\varepsilon=5.9 \%$. The parameters of the best reactor candidate are summarized in Table II, and the profiles are shown in Fig. 9. The broad temperature profile seems to be consistent with both interior heating from alpha particles and surface heating from the $\mathrm{rf}$.

Accessibility to lower hybrid waves demands [5] $n_{z} \geq 1+\omega_{p e}^{2} / \Omega_{e}^{2}$, where we compute the local plasma frequency from (7a) and the cyclotron frequency from $B(\rho)=B_{0} R / \rho$. This condition is plotted in Fig. 10 for the reference reactor, assuming waves are launched from the outside $(\rho>R)$. The figure confirms 
that spectra with $n_{z} \geq 1.2$ will propagate $25 \%$ of the distance into the plasma. Accessibility is somewhat easier for waves launched on the inside $(p<R)$, which is a definite possibility for a reactor design lacking a central solenoid. A more detailed study of accessibility in DT plasmas [21] yields a less optimistic result on this point; waves with $n_{z}=1.2$ would require low frequencies ( $f=0.836 \mathrm{GHz}, \omega=5.2 \mathrm{GHz}$ ) to penetrate $25 \%$ of the distance from the outside. Unfortunately this frequency is below the local lower hybrid frequency $\left(\omega_{L H}=8.26 \mathrm{GHz}\right.$ at $\left.\rho=R+0.75 \mathrm{a}\right)$, a condition which may allow parametric instabilities to grow, preventing lower hybrid wave penetration [22]. To avoid parametric decay we choose to operate at $f=1.5 \mathrm{GHz}$ with the consequence that those modes at the low $n_{z}$ end of the spectrum may not fully penetrate. Referring to Fig. 8 and Ref. 21 we find the whole problem can be avoided by selecting $n_{z}=1.55-1.80$, except that in this case $P_{r f}=65$ MN and $\varepsilon=3.2 \%$.

\section{REACTOR ENGINEERING}

The rf system parameters in Table II are based on a system [23] designed to deliver 50 IW of auxiliary heating power for tokamak startup. Although the system in Ref. 23 has different spectral characteristics $\left(f=2.4 \mathrm{GHz}, n_{z} \approx 3\right.$ ), it was pianned to handle the same $\mathrm{CW}$ power that we are considering and was designed to satisfy the neutronics, materials, and electronics requirements of a tokamak reactor. Note the modest area of waveguide grill required, $A_{W G}=$ $0.83 \mathrm{~m}^{2}$, compared to the first wall area, $A_{\text {wall }}=792 \mathrm{~m}^{2}$. The $\mathrm{rf}$ system was found to cost $75 \%$ as much as a $50 \mathrm{MW}$ neutral beam system for auxiliary heating. In addition, the reactor contairment building will be considerably smaller for rf compared to neutral beams; as shown in Fig. 11 the waveguides may be easily routed to a convenient external location. 
By not needing the Ohmic heating $(\mathrm{OH})$ solenoid in the central region it will be possible to place equilibrium field (EF) coils along the inner leg of the toroidal field (TF) magnet. By situating EF coils in this strategic location highly shaped plasmas may be formed with relatively modest amounts of energy stored in the EF coils [24]. Elimination of the $\mathrm{OH}$ coils also allows the installation of more structural support for the TF coils, which onens the option of using higher toroidal magnetic fields [25].

Operation without an $\mathrm{OH}$ transformer poses the problem of how to initiate the discharge using the $r f$ system. An emf develops around the torus from the changing equilibrium field during startup; let us consider a simple example in which the only external currents are those in the EF coils, denoted IEF, which have a mutual coupling $M$ to the plasma current, $I$. The emf is then

$$
v=-\frac{d(L I)}{d t}+\frac{M d I_{E F}}{d t},
$$

where $L$ is the plasma self-inductance. In the presence of both an emf and the rf wave, the electron current will consist of both the conventional dc component and the plateau current carriers, so $0 \mathrm{hm}$ 's law must be modified as

$$
I=\frac{V}{R^{N}}+I_{R F},
$$

where $R^{N}$ is the neoclassical resistance and $I_{R F}$ is the plateau current. These circuit equations can be solved for $I(t)$ with $I_{R F}(t)$ given as an input, subject to two constraints. First, the current in the EF corls must be consistent with that required for MHD equilibrium of the plasma current,

$$
I_{E F}=I_{E F}\left(I, n, T_{e}\right) \text {. }
$$


This is assured by solving the Grad-Shafranov equation for each time step during startup. Second, the resistance $R^{N}$ depends on plasma properties such as $T_{e}$, which are computed by simultaneously solving the dynamic zero-dimensional plasma transport equations for $n, T_{e}$, and $T_{i}$.

Que to increasing plasma current during startup, there is a reverse enif that induces a return current of bulk electrons that tend to cancel the plasma current $[5,6]$. As a result the plasma current requires a time $L / R^{N}$ to reach its steady-state value. At $T_{e}=8 \mathrm{keV}, L / R^{N}>10^{3} \mathrm{~s}$. Startup time can be reduced by maintaining a large plasma resistance $R^{N}$ to the return current of bulk carriers during startup, as will be shown in the example to follow.

This simulation was made for a reactor similar to the reference case; the parameters are not consistent with Table II, but the results are indicative for full-scale reactors. It was assumed that the rf-driven current is of the form $I_{R F}=I_{0} P_{r f} / P_{0}$, where $I_{0}=11.6 \mathrm{MA}$ and $P_{0}=20 \mathrm{MW}$. Figure 12 shows the results of the simulation. The period of $0-32 \mathrm{~s}$ is the main plasma current initiation phase, the period of about 32-41 s is the main heating phase, and from $41 \mathrm{~s}$ on, the plasma is in a steady-state configuration. The plasma density is composed of equal parts of deuterium and tritium and is ramped up from an average value of $0.5 \times 10^{20}$ to $1.53 \times 10^{20} \mathrm{~m}^{-3}$ in about $10 \mathrm{~s}$. It was found that the key to a successful startup is to control the applied rf power to the plasma very carefully. During the period 0-32 s, $\mathrm{P}_{\mathrm{rf}}$ was controlled according to the algorithm: $P_{\text {rf }}+P_{\alpha}-P_{R}-P_{T R}=1.0 \mathrm{MW}$, where $P_{\alpha}$ is the alpha heating power of the plasma, $P_{R}$ is the radiated power, and $P_{T R}$ is the thermal transport power out of the plasma. Physically, this formula ensures that there is a net heating power of 1 MW to the plasma, a relatively small amount. This keeps $\bar{T}_{e}$ low enough so that the resistivity can be kept high. 
As shown in the figure, the $r f$ heating power needs to be varied from about $5 \mathrm{MW}$ to $40 \mathrm{MW}$ during the $32-\mathrm{s}$ plasma current induction period. $\bar{T}_{\mathrm{e}}$ varies from $30 \mathrm{eV}$ to about $300 \mathrm{eV}$, which is much lower than would be obtainable if the $r f$ power would just be kept constant at $40 \mathrm{MW}$. The plasma current starts at $I=0$ at $t=0$ and reaches a value of $10 \mathrm{MA}$ at about $32 \mathrm{~s}$. During this period, the current in the EF coils has been ramped up continuously to keep the plasma in MHD equilibrium. At $32 \mathrm{~s}, \mathrm{P}_{\mathrm{rf}}$ is raised to $100 \mathrm{MW}$ in order to heat the plasma to ignition. During this main heating period, the EF current is raised to its final value, and this induces a further 1.6 MA of plasma current to bring I to its equilibrium value of $11.6 \mathrm{MA}$. When ignition is reached, $\mathrm{T}_{\mathrm{e}}=8.5 \mathrm{keV}$ and $\mathrm{P}_{\mathrm{rf}}$ is lowered to $20 \mathrm{MW}$ to maintain the current in steadystate operation.

It must be emphasized that, al though the current versus power algorithm used in this exercise $\left(I_{0} / P_{r f}=11.6 \mathrm{MA} / 20 \mathrm{MW}\right)$ is unrealistic, the results qualitatively assure us that startup is achievable on times much shorter than $L / R^{N}=10^{3} \mathrm{~s}$.

During the initiation of rf currents it will be desirable to adjust the $n_{z}$ spectrum to match the rf current profile to the changing plasma temperature and density profiles. Although a one-dimensional, time-dependent calculation is beyond the scope of our present investigation, we note that the rf system in Ref. 23 has been designed with electronic phase shifters which can be used to program $n_{z}(t)$.

Additional engineering advantages accrue to our reactor. The power supply configuration is simplified by the removal of the $\mathrm{OH}$ system and by the eliminaiion of the energy storage system required by pulsed tokamaks. It may be possible to fill the central hole with nonsaturated iron. This would tend to attract the plasma towards the center and, therefore, reduce the EF system requirements. 
The long startup times possible with a steady-state reactor would mean lower power requirements on the EF power supply. Steady-state operation also reduces fatigue problems in reactor materials [26], allowing longer first-wall lifetimes while using readily available austenitic stainless steel. Steady-state operation can alleviate the serious ratcheting problem which occurs at the uraniumciadding interface of any uranium compounds used in the blanket for fissilefuel breeding; this problem, which is due to the high thermal expansion coefficient of uranium, is one of the main reasons that fission plants are not used by utilities to follow fluctuating loads. Startup without the emf from an $\mathrm{OH}$ coil eliminates the need for resistive bellows or ceramic breaks in the first wall, which can improve the reactor reliability. Substitution of $r f$ for neutral beams also el iminates the need for a beam dump inside the torus.

The thermal-to-electric conversion efficiency, $\eta_{t h / a c}$, in Table II is typical of a high-temperature, lithium-cooled reactor [27].

Energy production in the blanket region from exothermic neutron reactions is assumed here to multiply the plasma's thermal power by a factor $f_{B}=1.2$. The net electric output, $\underset{\text { net }}{\mathrm{rf}}=780 \mathrm{MW}$, should be compared with that of a conventional tokamak reactor with, for example, a 95\% duty factor [27]: penventional
net

\section{CONCLUSIONS AND FUTURE WORK}

Steady-state tokamak reactors driven by $r f$ appear to offer a number of advantages over ohmically driven pulsed devices, despite the penalty paid in recirculating power. One of the most attractive possibilities is operating at very high stable $B_{t}$ values with force-free surface currents, a possibility which deserves additional attention. The whole question of current density stability and transport remains unexplored. Bootstrap currents and the emf 
induced by the EFC during startup will influence the current profile evolution. We note that hollow current profiles have been inferred for some present-day experiments [28]; it may be possible to simulate $j(r)$ evolution using onedimensional transport codes with MHD-type transport processes [29].

Additional outstanding problems are associated with steady-state fueling and impurity control. Impurity buildup may, in fact, limit pulse lengths, even though transformer volt-second limitations can be removed with the use of rf-driven currents. Even in such a situation, an rf-driven reactor may prove competitive with a transformer-driven mode1; the engineering and economic tradeoffs between these alternatives must await further detailed analysis.

\section{ACKNOWLEDGMENTS}

I thank $\mathrm{J}$. Norem for suggesting and encouraging this investigation and N. Fisch for many enlightening conversations. The help of K. Evans, Jr., was invaluable in computing the MHD equilibria, and the efforts of W. Marable were instrumental in refining and debugging the rf-damping code. I am indebted to J. Brooks for performing the dynamic simulation shown in Fig. 12, H. Stevens for Fig. 11, and to S. Harkness for discussions regarding materials problems. 


\section{REFERENCES}

[1] LALliA, P., in Plasma Heating in Toroidal Devices (Proc. 3rd Int. Symp. Varenna, 1976), 84.

[2] BRAMBILLA, M., Nuc1. Fusion 16 (1976) 47.

[3] BERNABEI, S., HEALD, M. A., HOOKE, W. M., MOTLEY, R. W., PAOLONI, F. J., BRAMBILLA, M., GETTY, W. D., Nucl. Fusion 17 (1977) 929.

[4] SAgdeEV, R. Z., GALEEV, A. A., Nonl inear Plasma Waves, Benjamin, New York (1969), Chapter II.

[5] FISCH, N. J., Phys. Rev. Lett. 41 (1978) 873.

[6] FISCH, N. J., Ph.D. thesis, MIT (1978).

[7] KARNEY, C. F. F., FISCH, N. J., Princeton Plasma Physics Lab., PPPL-1506 (1979).

[8] STIX, T. H., The Theory of Plasma Waves, McGraw-Hill, New York (1962).

[9] BELLAN, P. M., PORKOLAB, M., Phys. Fluids 19 (1976) 995.

[10] CALLEN, J. D., DORY, R. A., Phys. Fluids 15 (1975) 1523.

[11] EHST, D. A., EVANS, K., JR., STACEY, W. M., JR., Nucl. Technol., to be published.

[12] GALVAO, R. M. 0., Nucl. Fusion 15 (1975) 785.

[13] DOBROTT, D., HELTON, F. J., Nucl. Fusion 16 (1976) 491.

[14] BATEMAN, G., PENG, Y-K. M., Phys. Rev. Lett. 38 (1977) 829.

[15] PENG, Y-K. M., DORY, R. A., NELSON, D. B., SAYER, R. 0., Phys. Fluids 21 (7978) 467 .

[16] TODD, A. M. M., MANICKAM, J., OKABAYASHI, M., CHANCE, M. S., GRIMM, R. C., GREEN, J. M., JOHNSON, J. L., Princeton Plasma Physics Laboratory, PPPL-1470 (1978), submitted to Nucl. Fusion. 
[17] D'IPPLITO, D. A., FREIdDERG, J. P., GOEdBLOED, J. P., REM, J., In PlaPhysics and Controlled Nuclear Fusion Research, 1976 (Proc. 6th Int. Conf. Berchtesgaden, 1976) I, IAEA, Vienna (1977) 537.

[18] D'IPPOLITO, D. A., FRIEDBERG, J. P., GOEDELOED, J. P., REM, J., Phys. Fluids 21 (1978) 1600.

[19] BOBELdIJK, l., hOEKZEMA, J. A., MIMIJRA, M., OEPTS, D., OOMENS, A. A. M., in Plasma Physics and Controlled Nuclear Fusion Research (Proc. 6tr. Int. Conf. Berchtesgaden, 1976) I, IAEA, Vienna (1977) 493.

[20] ABDOU, M., J. Nucl. Mater. $\underline{72}$ (1978) 142.

[21] hicker, M. P., HARVEY, R. W., General Atomic Company, GA-A14933 (1978).

[22] PORKOLAB, M., Phys. Fluids 20 (1977) 2058.

[23] BROOKS, J., hARKNESS, S., JUNG, J., MISRA, B., MORETTI, A., NOREM, J., STEVENS, H., Argonne National Lab., ANL/FPP/TM-103 (1978); also presented at 3rd Top. Conf. on RF Plasma Heating (Pasadena, 1978).

[24] EVANS, K., JR., EHST, D. A., MESSERSCHMIDT, P., presented at 3rd Top. Mtg. on Technology of Controlled Nuclear Fusion (Santa Fe, 1978).

[25] COHN, D. R., PARKER, R. R., JASSBY, D. L., Nucl. Fusion 16 (1976) 37; also, JASSBY, D. L., Princeton Plasma Physics Lab., PPPL-1371 (1977).

[26] MAJUMDAR, S., MISRA, B., HARKNESS, S., presented at Int. Atomic Energy Agency Workshop on Fusion Reactor Design (Madison, 1977), paper IAEATC-145/35.

[27] ARONSTEIN, R. E., GHOSE, S. K., in Trans. Am. Nucl. SOc. 26 (1977) 45.

[28] BERRY, L. A., ET AL., in Plasma Physics and Controlled Nuclear Fusion Research (Proc. 6th Int. Conf. Berchtesgaden, 1976) I, IAEA, Vienna (1977) 49; also, ARUNASALAM, V., ET AL., Princeton Plasma Physics Lab., PPPL-1436 (1978).

[29] HOULBERG, W. A., HOGAN, J. T., Bull. Am. Phys. Soc. 23 (1978) 760. 
TABLE I. Reactor Survey

\begin{tabular}{|c|c|c|c|c|c|c|c|}
\hline$\alpha_{n}$ & $\alpha_{T}$ & $\begin{array}{c}\overline{T_{e}} \\
(\mathrm{keV})\end{array}$ & $\begin{array}{c}\bar{T}_{f} \\
(\mathrm{keV})\end{array}$ & $\begin{array}{c}\bar{n}_{e} \\
\left(10^{19} m^{-3}\right)\end{array}$ & $\begin{array}{c}\tau \\
(s)\end{array}$ & $\underset{(M W)}{P_{f}}$ & $\begin{array}{c}P_{W} \\
\left(M W / m^{2}\right)\end{array}$ \\
\hline $\begin{array}{l}0.9 \\
0.9 \\
0.9 \\
0.9\end{array}$ & $\begin{array}{l}1.1 \\
1.1 \\
1.1 \\
1.1\end{array}$ & $\begin{array}{l}10 \\
18 \\
26 \\
34\end{array}$ & $\begin{array}{r}9.86 \\
19.1 \\
31.3 \\
\end{array}$ & $\begin{array}{r}13.9 \\
7.03 \\
4.52 \\
\end{array}$ & $\begin{array}{l}1.91 \\
2.90 \\
5.85 \\
>10\end{array}$ & $\begin{array}{r}2420 \\
1450 \\
772 \\
\end{array}$ & $\begin{array}{l}2.44 \\
1.46 \\
0.781 \\
\end{array}$ \\
\hline $\begin{array}{l}1.3 \\
1.3 \\
1.3 \\
1.3\end{array}$ & $\begin{array}{l}0.7 \\
0.7 \\
0.7 \\
0.7\end{array}$ & $\begin{array}{l}10 \\
18 \\
26 \\
34\end{array}$ & $\begin{array}{l}9.82 \\
18.6 \\
30.4 \\
45.0\end{array}$ & $\begin{array}{c}14.4 \\
7.32 \\
4.67 \\
3.42\end{array}$ & $\begin{array}{c}1.89 \\
2.50 \\
4.70 \\
10.8\end{array}$ & $\begin{array}{r}2540 \\
1690 \\
936 \\
512\end{array}$ & $\begin{array}{l}2.56 \\
1.71 \\
0.947 \\
0.517\end{array}$ \\
\hline $\begin{array}{l}1.7 \\
1.7 \\
1.7 \\
1.7\end{array}$ & $\begin{array}{l}0.3 \\
0.3 \\
0.3 \\
0.3\end{array}$ & $\begin{array}{l}10 \\
18 \\
26 \\
34\end{array}$ & $\begin{array}{l}9.84 \\
18.1 \\
28.7 \\
41.8\end{array}$ & $\begin{array}{c}16.0 \\
8.31 \\
5.29 \\
3.85\end{array}$ & $\begin{array}{l}1.99 \\
2.15 \\
3.43 \\
6.46\end{array}$ & $\begin{array}{r}2580 \\
2010 \\
1250 \\
738\end{array}$ & $\begin{array}{l}2.61 \\
2.03 \\
1.26 \\
0.746\end{array}$ \\
\hline
\end{tabular}

$\tau$ is containment time.

$\mathrm{P}_{\mathrm{w}}$ is neutron wall loading. 
TABLE II. Reactor with Surface Currents at Moderate $B_{t}$

Equilibrlum: $\quad A=3.0, \quad k=1.3, \quad d=0.25, \quad \alpha=2.0$,

$B_{t}=0.07, \quad q(0)=1.3, \quad q(a)=3.9$

Plasma:

$$
\begin{aligned}
& \bar{T}_{e}=18.0 \mathrm{keV}, \quad \bar{T}_{1}=18.1 \mathrm{keV} \\
& \bar{n}_{e}=8.31 \times 10^{19} \mathrm{~m}^{-3}, \quad \alpha_{\mathrm{n}}=1.7, \quad \alpha_{\mathrm{T}}=0.3 \\
& Z_{\text {eff }}=1.7, \quad \tau=2.15 \mathrm{~s}
\end{aligned}
$$

Design:

$$
\begin{aligned}
& R=7.0 \mathrm{~m}, \quad B_{\max }=9.0 \mathrm{~T}, \quad A_{w a 11}=792 \mathrm{~m}^{2} \\
& \Delta_{B / \mathrm{s}}^{i}+\Delta_{v}=1.2 \mathrm{~m}, \quad B_{0}=4.46 \mathrm{~T}
\end{aligned}
$$

RF System:

$$
\begin{array}{ll}
n_{z}=1.2-1.6, & P_{r f}=56 \mathrm{MW} \\
I_{W G}=67 \mathrm{MW} / \mathrm{m}^{2} & \\
A_{W G}=0.83 \mathrm{~m}^{2} & \\
f=1.5 \mathrm{GHz}, & n_{\mathrm{ac} / \mathrm{rf}}=0.41
\end{array}
$$

Performance: $\quad P_{f}=2010, \quad I=9.8 \mathrm{MA}$

$$
\begin{aligned}
& \varepsilon=2.8 \%, \quad \text { Duty cycle }=100 \% \\
& f_{B}=1.2, \quad \eta_{t h / a c}=0.38 \\
& P_{w}=2.03 \mathrm{MW} / \mathrm{m}^{2} \\
& P_{\text {net }}^{r f}=P_{f} \times f_{B} \times n_{t h / a c}-P_{r f} n_{a c / r f}^{-1}=780 \mathrm{MW}
\end{aligned}
$$




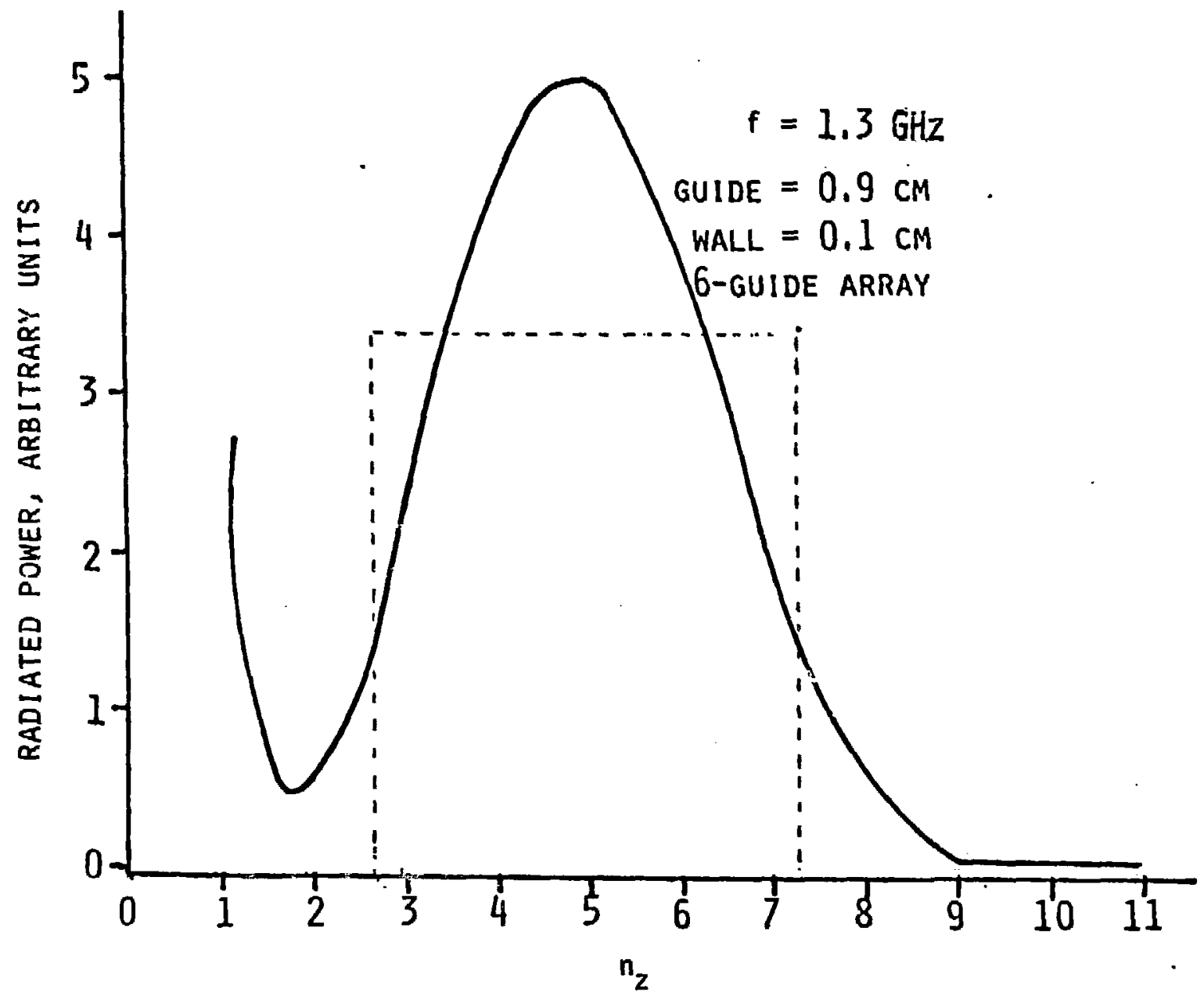

FIG. 1. Typical spectrum from Brambilla grill. 


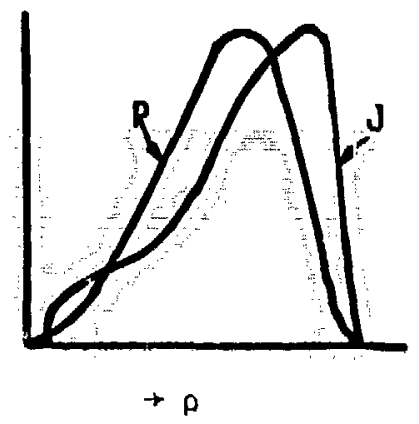

FIG. 2. Centrally peaked current equilibrium: $A=3.0, k=1.0, d=0.0, \alpha=1.4, B_{t}=0.06$, $q(0)=1.0, q(a)=3.0$.

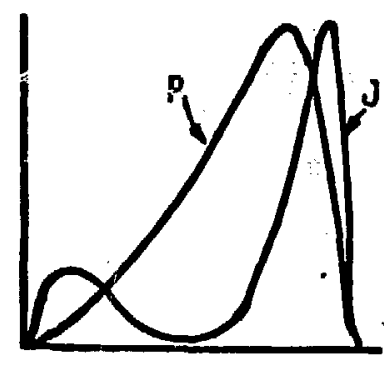

$\rightarrow \rho$

Fig. 3. Surface current equilibrium: $A=3.0$, $k=1.3, d=0.25, \alpha=2.0 ; \beta_{t}=0.12$ when $q$ varies between 1.0 and $3.0 ; \beta_{t}=0.07$ when $q$ varies between 1.3 and 3.9 .

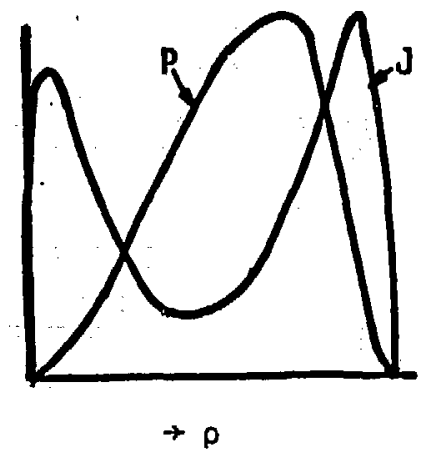

Fig. 4. Force-free current equilibrium: $A=2.5$, $k=1.0, d=0.0, \alpha=2.0 ; \beta_{t}=0.16, q(a) * q(0)$ $=1.0$; this figure is reproduced from Ref. 17. 


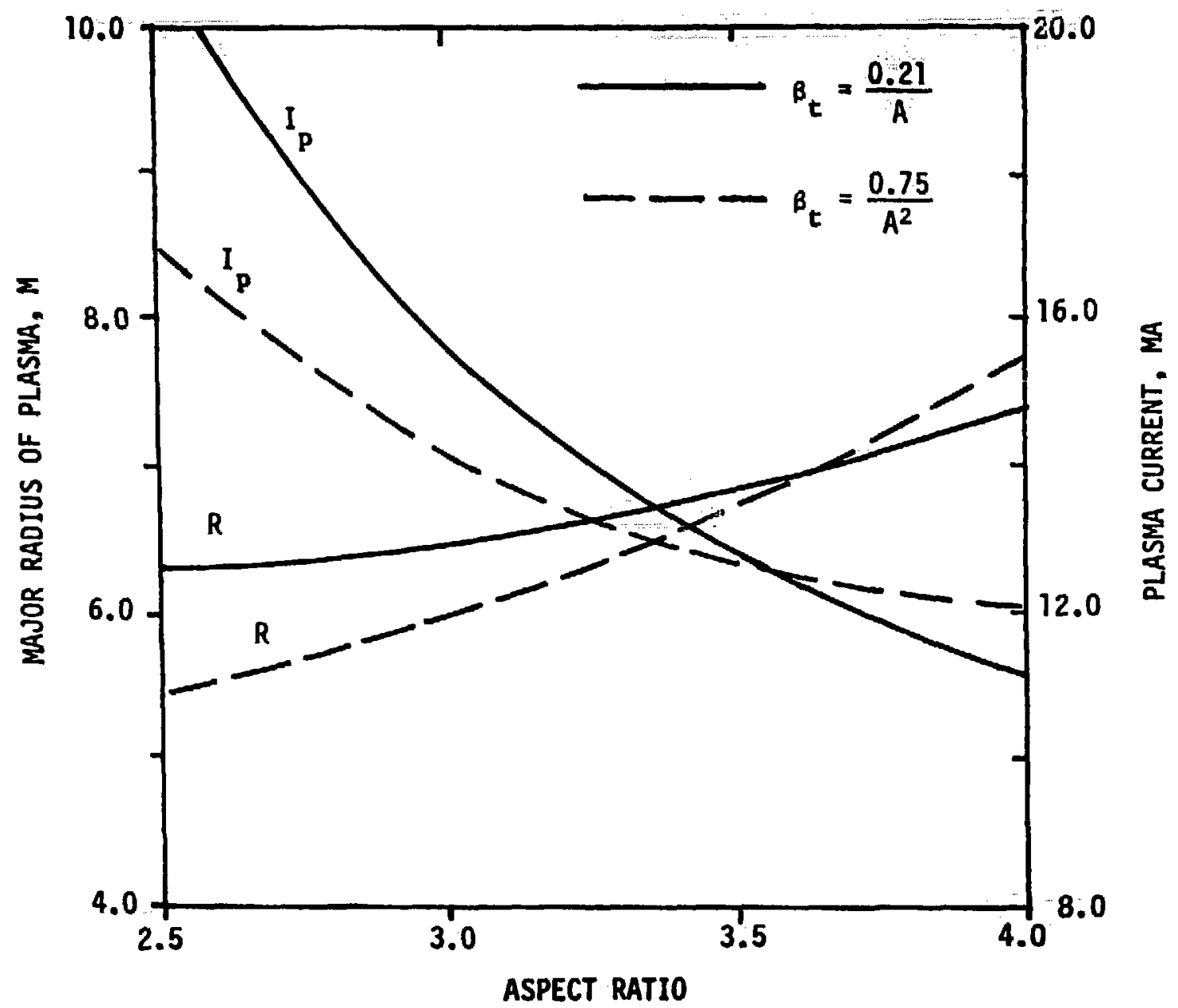

FIG. 5. Major radius and plasma curreit for various beta scalings; $P=2500 \mathrm{MW}, B=9.0 \mathrm{~T}, q_{a}=3.0, \alpha=1.4, \Delta_{B / \mathrm{s}}^{1}=1.0 \mathrm{~m}, \mathrm{k}=1.65$, $d=0.5$, centrally peaked current equilibria. This figure is reproduced from Ref. 11. 


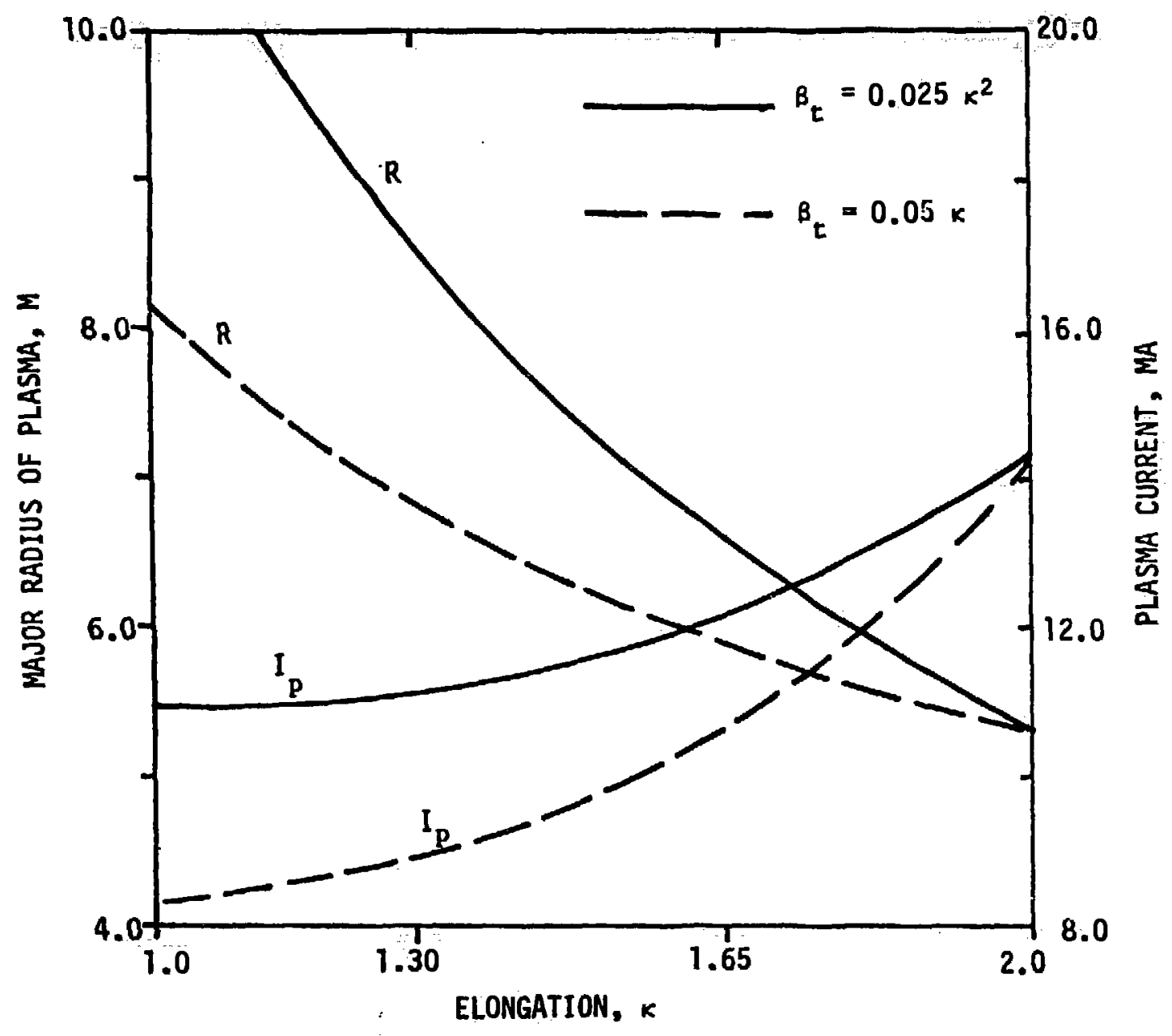

FIG. 6. Major radius and plasma current for various beta scalings; $P=2500 \mathrm{MW}, \mathrm{B}=9.0 \mathrm{~T}, \mathrm{q}_{\mathrm{a}}=3.0, \alpha=1.4, \Delta_{\mathrm{B} / \mathrm{s}}^{i}=1.0 \mathrm{~m}, \mathrm{~A}=3.5$, centrally peaked current equilibria. This figure is reproduced from Ref. 11. 


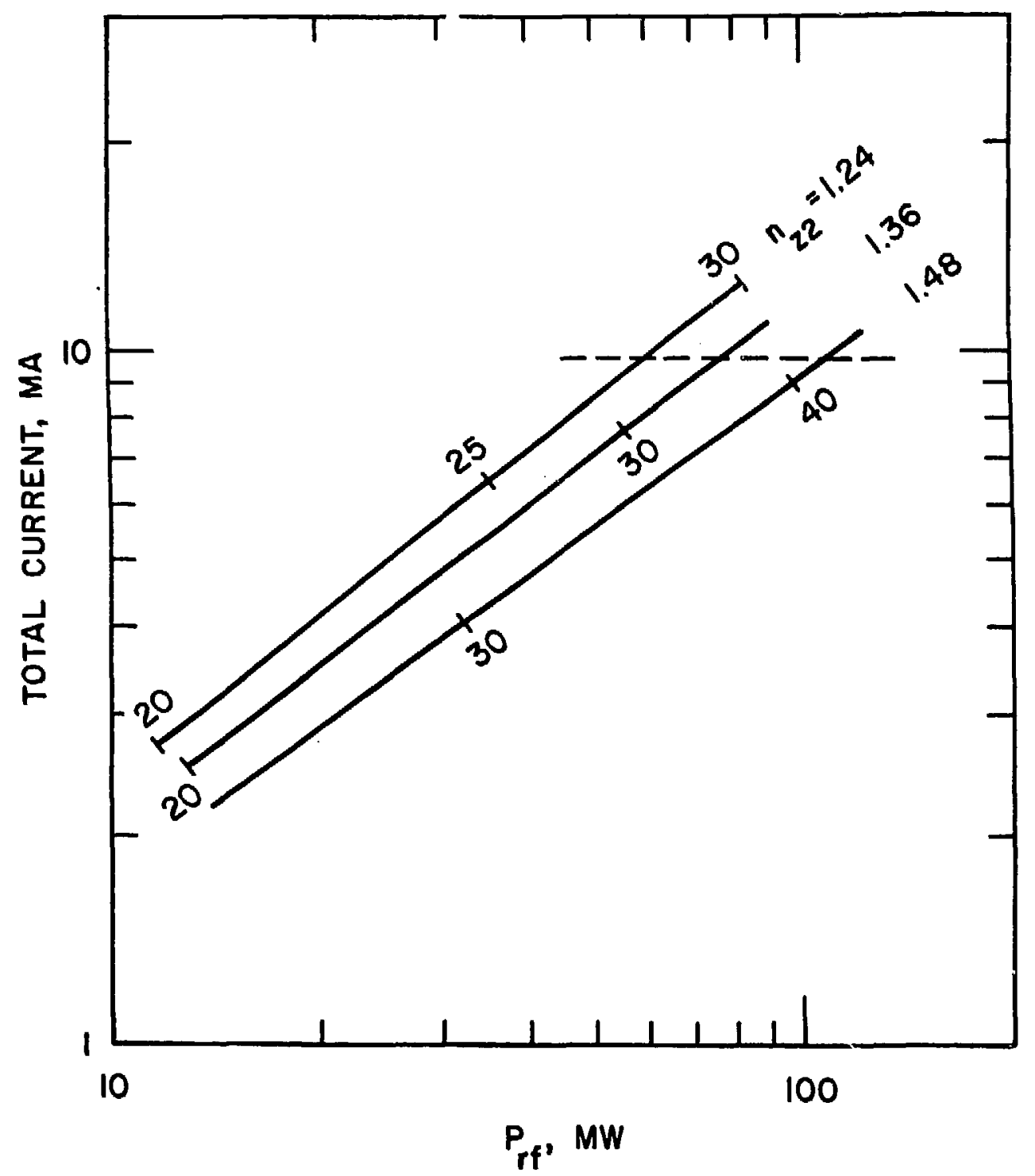

FIG . 7. Total current and $\mathrm{rf}$ power for $\overline{\mathrm{T}}_{e}=18 \mathrm{keV}, \alpha_{n}=1.7$, and $n_{z 1}=1.60$. Percent of wave penetration is indicated on curves; $I=9.8 \mathrm{MA}$ is required for equilibrium.

(ANL Neg. No. 190-79-44) 


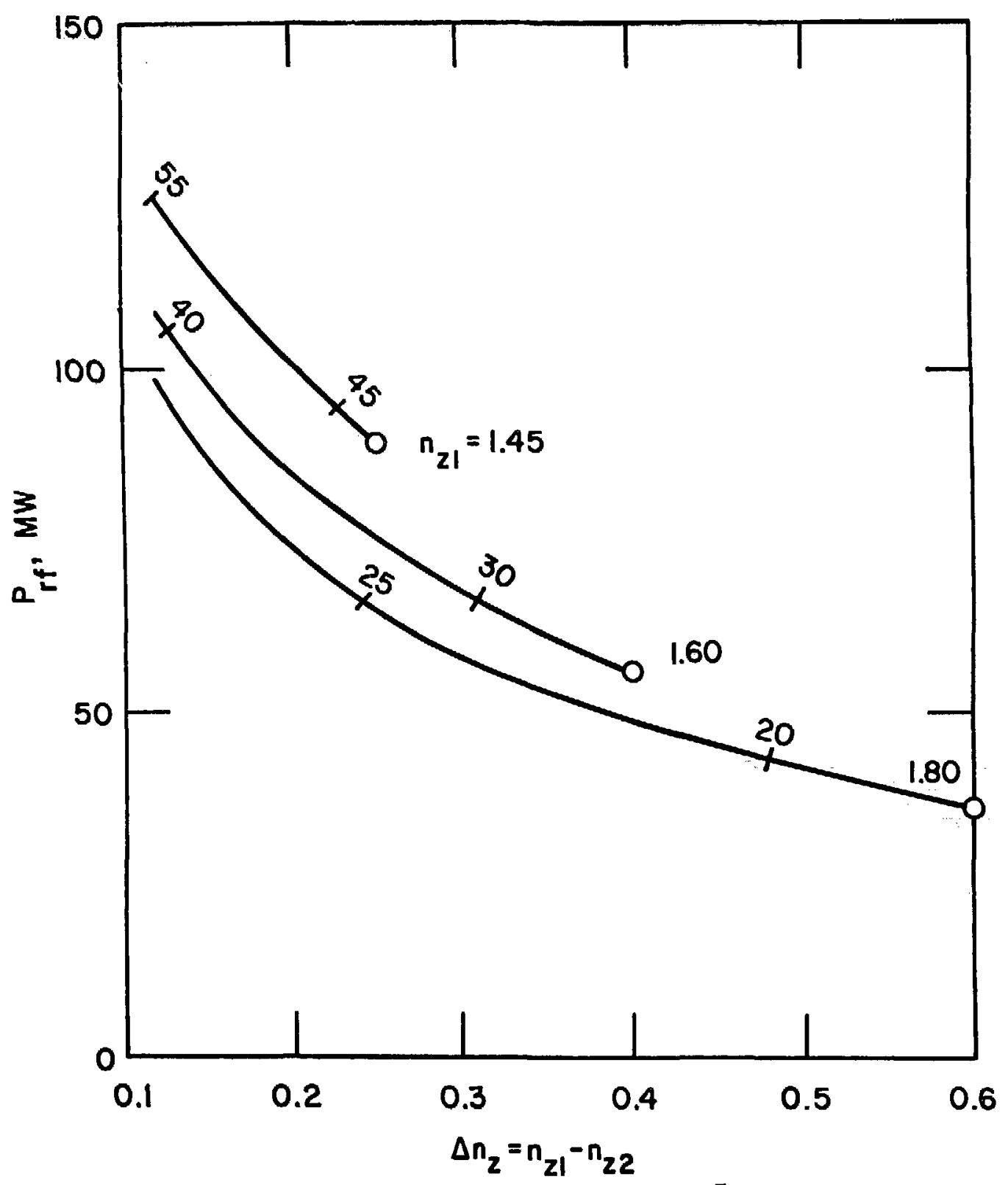

FIG. 8. Required rf power for reactor with $\bar{T}_{e}=18 \mathrm{keV}$ and $\alpha_{n}=1.7$ for several spectra. Percent penetration is indicated along curves.

(ANL Neg. No. 190-79-42) 


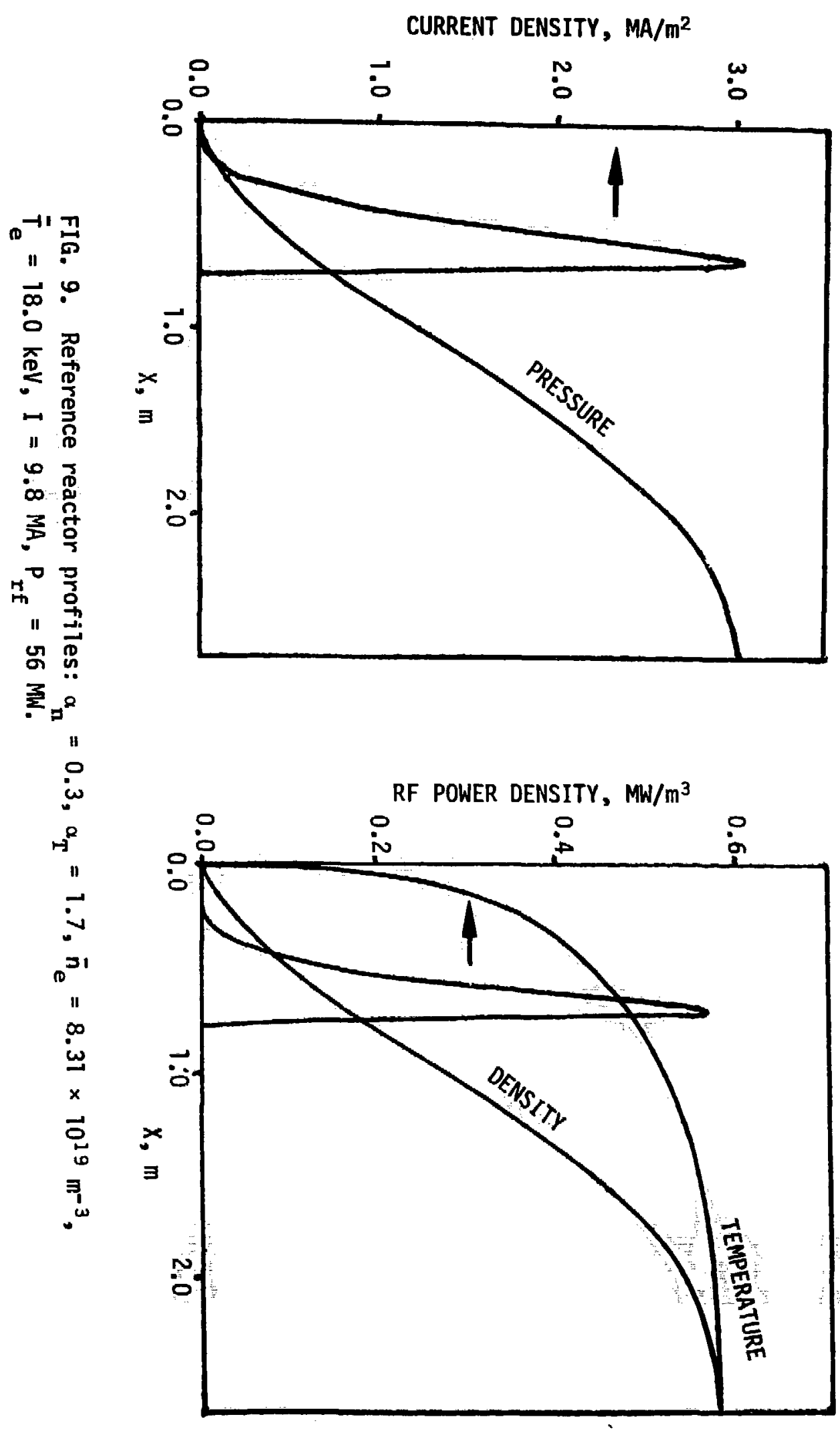




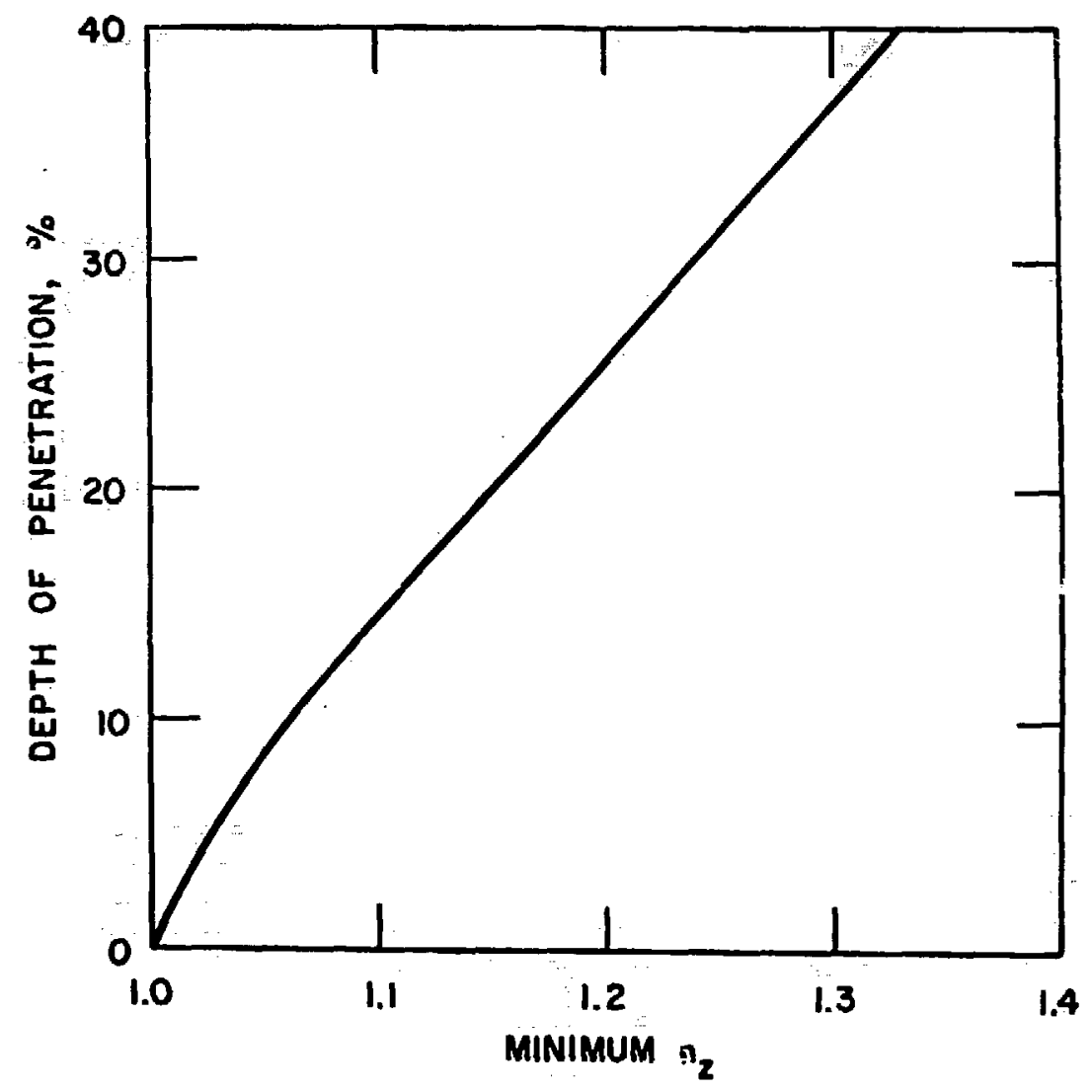

FIG. 10. Lower hybrid wave accessibility.

(ANL Neg. No. 190-79-44) 


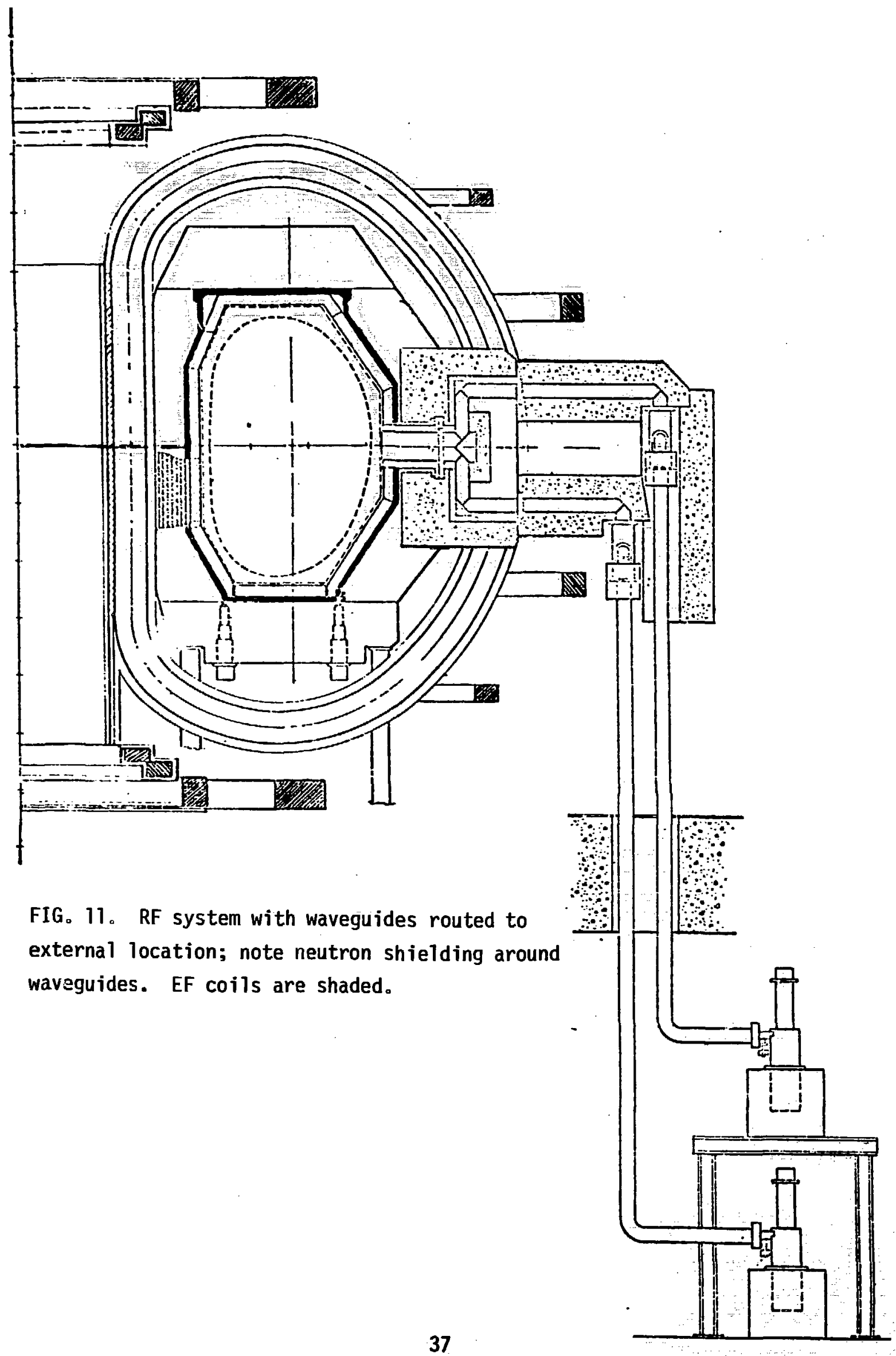




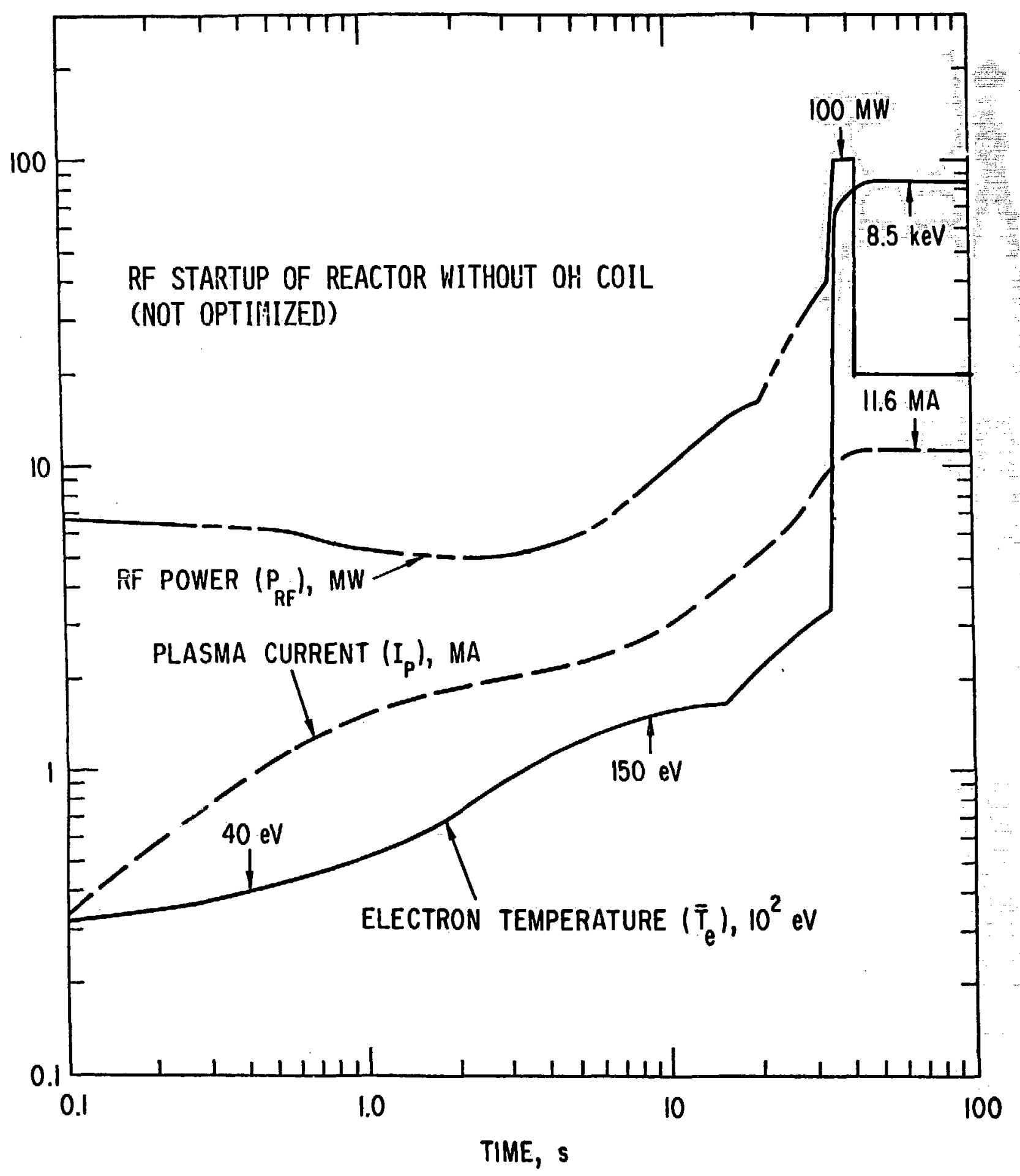

FIG. 12. Typical reactor parameters during startup. 
Internal

P. I. Amundson

C. C. Baker

E. F. Bennett

S. Bhattacharyya

C. D. Boley

J. N. Brooks

F. A. Cafasso

Y. I. Chang

R. G. Clemer

J. B. Darby

D. Ehst (20)

K. Evans, Jr.

J. A. Fasolo

R. E. Fuja

G. T. Garvey

E. M. Gelbard

M. Y. Gohar

L. R. Greenwood

D. M. Gruen

S. D. Harkness

H. Henryson

H. H. Hummel

M. S. Kaminsky

Y. -K. Kim

A. B. Krisciunas

J, Krazinski

R. L. Kustom

L. G. LeSage

V. A. Maroni

R. L. Martin

F. V. Nolfi

J. H. Norem

P. J. Persian1

E. N. Pettitt

E. G. Pewitt

A. B. Smith

D. L. Smith

H. C. Stevens

W. J. Sturm

F. W. Thalgott

C. E. TH1I

A. Travelli

L. Turner

D. Wade

S. - T. Wang

FP Program (2)

ANL Contract Copy

ANL Libraries (5)

TIS Files (5)

\section{External}

DOE-TIC, for distribution per UC-20a and -20d (181)

Manager, Chicago Operations office - DOE

Chief, Office of Patent Counsel, $\mathrm{CH}$

President, Argonne Universities Association

Applled Physics Division Review Comnittee:

P. W. Dickson, Jr., Westinghouse Electric Corporation

R. ' L. Hellens, Combustion Engineering, Inc.

W. B. Loewenstein, electric Power Research Institute

R. Fa Redmond, Ohio State University

R. Sher, Stanford University

D. B. Wehmeyer, Detroit Edison

K. D. Lathrop, Los Alamos Scientific Laboratory

M. Abdou, Georgia Institute of Technology

T. Antonsen, Massachusetts Institute of Technology

V. L. Bailey, Physics International, San Leandro

R. W. Bass, Provo, Utah

P. Bellan, California Institute of Technology

A. Bers, Massachusetts Institute of Technology 
D. Blackfield, University of Wisconsin

S. J. Bucksbaum, Bell Telephone Laboratories, Inc., Holmdel, N. J.

J. A. Casazza, Stone \& Webster Management Consultants, Inc., New York, N. Y.

F. Chang, Draper Laboratory, Cambridge, Mass.

H. Derfler, Max-Planck-Institute fur Plasmaphysik

T. J. Dolan, University of Missouri-Rolla

T. H. Dupree, Massachusetts Institute of Technology

T. S. Elleman, North Carolina State University

J. Feinstein, Varian Associates, Inc.

H. Finger, Center of Energy Systems, Washington, D. C.

N. Fisch, University of Princeton Plasma Physics Laboratory

J. Fisher, Draper Laboratory, Cambridge, Mass.

H. K. Forsen, Exxon Nuclear Company, Inc., Bellevue, Wash.

J. S. Foster, TRW, Redondo Beach

J. Freidberg, Los Mlamos Scientific Laboratory

E. A. Frieman, University of Princeton Plasma Physics Laboratory

W. Getty, University of Michigan

D. Grafstein, Exxon Research and Engineering Company, Linden. N. J.

G. Hansen, Convair Division, General Dynamics

R. Harvey, General Atomic Company

A. F. Haught, United Technologies Research Center

M. Heald, Massachusetts Institute of Technology

I. G. Hedrich, Grumman Aerospace Corporation

N. Hershkowitz, University of Iowa

J. Hogan, Oak Ridge National Laboratory

W. Houlberg, Oak Ridge National Laboratory

R. A. Huse, Public Service Electric and Gas Company, Newark, N. J.

D. Kaplan, Massachusetts Institute of Technology

C. Karney; University of Princeton Plasma Physics Laboratory

M. Katsurai, University of Princeton Plasma Physics Laboratory

D. Keifer, EG\&G Company, Idaho Falls

Y. Kiwamoto, University of California-Irvine

A. Kolb, Maxwe11 Laboratory, San Diego

W. B. Kunke1, University of California-Berkeley

B. Kusse, Cornell University.

R. Ia Haye, General Atomic Company

L. Lang, University of Wisconsin

L. M. Lidsky, Massachusetts Institute of Technology

S. Luckhardt, Cornell University

S. H. Lull, Northeast Utility Service Company, Hartford, Conn.

W. M. Marable, Masschusetts Institute of Technology

S. Naymark, Nuclear Services Corporation

L. Olson, University of Princeton Plasma Physics Laboratory

F. W. Perkins, University of Princeton Plasma Physics Laboratory

M. Porkolab, Masschusetts Institute of Technology

R. Prater, General Atomic Company

J. Rawls, General Atomic Company

M. Read, Naval Research Laboratory

J. Rem, EURATOM-FOM, Netherlands

I. P. Shkarofsky, MPB Technologies Institute, Quebec

L. Shohet, University of Wisconsin

D. J. Sigmar, Oak Ridge National Laboratory 
W. M. Stacey, Jr., Georgia Institute of Technology

D. R. Sweetman, Culham Laboratory

S. Tamor, Science Applications, Inc.

R. Temkin, Masschusetts Institute of Technology

S. Wolfe, Massachusetts Institute of Technology

T. F. Yang, Westinghouse Electric Company

K. Yoshikawa, Lawrence Livermore Laboratory - University of California

T. Young, Physics International, San Leandro

S. Y. Yuen, Massachusetts Institute of Technology

N. Winsor, Naval Research Laboratory 